\title{
Geographical distribution of genetic diversity in Secale landrace and wild accessions
}

\author{
Jenny Hagenblad ${ }^{1 \dagger}$, Hugo R. Oliveira ${ }^{1,2,3,4^{*}}$, Nils E. G. Forsberg ${ }^{1}$ and Matti W. Leino ${ }^{1,3}$
}

\begin{abstract}
Background: Rye, Secale cereale L., has historically been a crop of major importance and is still a key cereal in many parts of Europe. Single populations of cultivated rye have been shown to capture a large proportion of the genetic diversity present in the species, but the distribution of genetic diversity in subspecies and across geographical areas is largely unknown. Here we explore the structure of genetic diversity in landrace rye and relate it to that of wild and feral relatives.

Results: A total of 567 SNPs were analysed in 434 individuals from 76 accessions of wild, feral and cultivated rye. Genetic diversity was highest in cultivated rye, slightly lower in feral rye taxa and significantly lower in the wild S. strictum Presl. and S. africanum Stapf. Evaluation of effects from ascertainment bias suggests underestimation of diversity primarily in S. strictum and S. africanum. Levels of ascertainment bias, STRUCTURE and principal component analyses all supported the proposed classification of $S$. africanum and S. strictum as a separate species from S. cereale. S. afghanicum (Vav.) Roshev, S. ancestrale Zhuk, S. dighoricum (Vav.) Roshev, S. segetale (Zhuk.) Roshev and S. vavilovii Grossh. seemed, in contrast, to share the same gene pool as $S$. cereale and their genetic clustering was more dependent on geographical origin than taxonomic classification. S. vavilovii was found to be the most likely wild ancestor of cultivated rye. Among cultivated rye landraces from Europe, Asia and North Africa five geographically discrete genetic clusters were identified. These had only limited overlap with major agro-climatic zones. Slash-and-burn rye from the Finnmark area in Scandinavia formed a distinct cluster with little similarity to other landrace ryes. Regional studies of Northern and South-West Europe demonstrate different genetic distribution patterns as a result of varying cultivation intensity.

Conclusions: With the exception of S. strictum and S. africanum different rye taxa share the majority of the genetic variation. Due to the vast sharing of genetic diversity within the $S$. cereale clade, ascertainment bias seems to be a lesser problem in rye than in predominantly selfing species. By exploiting within accession diversity geographic structure can be shown on a much finer scale than previously reported.
\end{abstract}

Keywords: Rye, Population structure, SNP, Ascertainment bias, Genetic variation, Phylogeography

\section{Background}

Rye (Secale cereale L.) has the ability to thrive and to produce high yields also under adverse environmental conditions $[1,2]$. It is unique amongst old-world graminoid cereals for being an out-breeder (wind cross-pollinated)

\footnotetext{
* Correspondence: hugo.oliveira@manchester.ac.uk

${ }^{\dagger}$ Equal contributors

'IFM Biology, Linköping University, SE-581 83 Linköping, Sweden

${ }^{2} \mathrm{CIBIO}-$ Research Centre in Biodiversity and Genetic Resources, Campus Agrário de Vairão. R. Padre Armando Quintas, 4485-661 Vairão, Portugal Full list of author information is available at the end of the article
}

and thus constitutes an important species for comparative studies in crop evolution. Turkey, Transcaucasia, Iran and Central Asia are believed to be centres of domestication of rye but it is still unclear which route rye followed as it was introduced into Europe: north of the Black and Caspian seas into central Europe (and from here to the Balkans) or along the Mediterranean route followed by the other Neolithic cereals [3]. Rye was long a staple crop in central and northern Europe and Russia, but has been cultivated to a much lesser extent in other parts of Europe. In Fennoscandia (Finland, Sweden, Norway and Denmark), rye became a dominant food crop in early Medieval times 
$[4,5]$. Especially in Finland rye was a staple crop and the main produce in the slash-and-burn farming systems practiced until the early $20^{\text {th }}$ century [6]. During the $20^{\text {th }}$ century, rye cultivation in Europe, including Fennoscandia, declined and the worldwide rye production was 16.7 million tonnes in 2013, making it only the $24^{\text {th }}$ most produced crop [http://faostat3.fao.org].

Cultivated rye is a diploid annual grass. Different taxonomies have been proposed for the genus Secale [7-10]. Recent studies have been conducted using molecular markers such as rDNA-ITS [11], 5S-rDNA [12], AFLPs $[13,14]$ and SSRs [15], but the taxonomy of the genus remains inconclusive. The relationship between cultivated, weedy, feral and true wild forms is also elusive [16]. For its simplicity, in this paper we follow the Sencer and Hawkes [8] classification with cultivated rye classified as the species Secale cereale subsp. cereale. Within the S. cereale species some weedy forms are included (ie: subsp. segetale, dighoricum, afghanicum and ancestrale). These weedy forms, here called feral, occur as weeds in cereal fields, mostly in the Near East and Central Asia and are fully inter-fertile with cultivated rye [17].

Wild ryes related to cultivated rye include $S$. vavilovii (ie: S. cereale subsp. vavilovii), distributed throughout southwest Asia, and S. strictum, occurring throughout the Mediterranean Basin, Southwest Asia, Caucasus and Central Asia $[8,18]$. These wild ryes, especially $S$. vavilovii, can hybridise with $S$. cereale [8]. It is still debated whether cultivated rye was domesticated from one or both of these two wild species [19]. In the most recent morphologybased taxonomy Frederiksen and Petersen [10] considered only three species: the annual wild $S$. sylvestre; the perennial wild $S$. strictum (= S. montanum) (with subspecies strictum, africanum, and anatolicum); and S. cereale, including cultivated and weedy rye and vavilovii as subspecies.

In many crops a large proportion of the genetic diversity of the species can be found in unimproved domesticated varieties, known as landraces. These can be defined as "dynamic population(s) of a cultivated plant that has historical origin, distinct identity and lacks formal crop improvement, as well as often being genetically diverse, locally adapted and associated with traditional farming systems" [20]. As a result of long lasting cultivation at their particular locations, landraces are likely to reflect the historical origins and the selection and adaptation processes affecting crops [21]. Thus, crop landraces are a superior material compared to elite breeds when it comes to the investigation of the distribution of genetic diversity resulting from crop evolutionary processes. Genebanks worldwide hold thousands of rye landrace accessions as well as seeds of feral and wild forms, preserving a vast diversity of agronomically relevant genes and traits.
The distribution of genetic diversity in different taxa of rye has been examined by various molecular marker systems. Persson \& von Bothmer [22, 23] used isoenzymes and RAPDs to study landraces and cultivars from Northern Europe but found no clear structuring from geography or improvement status. Chikmawati et al. [13, 14] used AFLP and a worldwide collection of cultivated, wild and weedy rye. In their study, the wild and weedy rye was separated from the cultivated rye, but no geographic structure was found among the cultivated accessions. Recently, Bolibok-Bragoszewska et al. [24] used a massive pooling strategy and dominant DaRT markers to investigate genetic structuring among elite breeds, landraces and wild ryes. Taxon and breeding status was found to result in some genetic structuring whereas geography was mostly unrelated to genetic distribution. A common observation of the studies mentioned above is the high degree of variation found within groups and not among them. Consequently, to find geographic genetic structuring, high power in terms of marker number and individuals is needed. It is thus unfortunate that with the exception of the studies by Persson \& von Bothmer [22, 23] withinaccession diversity has not been explored in rye.

Lately single nucleotide polymorphisms (SNPs) have become the preferred molecular markers in crop genomics because of their high frequency across genomes and their amenability to cost-effective high-throughput assays [25]. SNPs are suitable markers for studying population structure and evolutionary processes in cereals and have been applied in the study of rice [26, 27], maize [28, 29], wheat [30, 31] and barley [32-34]. Recent efforts have resulted in SNP panels being developed also in rye [35-37] thereby allowing geographic structure and evolution to be investigated also in this outbreeding crop.

Our understanding of the evolution of domesticated plants in the Old World has mainly been based on selfpollinating plants with a long domestication history (e.g. wheat, rice, barley). In this paper we thus address the following questions: 1) How is genetic diversity distributed within and between populations of cultivated, wild and feral rye? 2) Does population structure corroborate the taxonomy of rye and from which wild species was rye domesticated? 3) Can we detect geographic structuring of genetic diversity in landrace rye and if so on which scale? For this purpose we genotyped a panel of 768 SNPs distributed throughout the rye genome in rye landraces and in feral and wild rye accessions.

\section{Materials and methods Plant material}

A panel consisting of 468 individual plants belonging to 80 rye accessions from a broad geographic range including Europe, Morocco, Near East, Russia and Central Asia was assembled (Table 1; Additional file 1). 
Table 1 Accessions used in this study: their type, taxonomical classification and geographical provenance

\begin{tabular}{|c|c|c|c|c|}
\hline Type & Taxon & $\begin{array}{l}\text { No. of } \\
\text { accessions }\end{array}$ & $\begin{array}{l}\text { No. of } \\
\text { individuals }\end{array}$ & Provenance \\
\hline Wild & $\begin{array}{l}\text { S. strictum, S. africanum, S. } \\
\text { vavilovii }\end{array}$ & 8 & 44 & Iran, Italy, South Africa, Turkey. \\
\hline Feral & $\begin{array}{l}\text { S. cereale subsp. afghanicum, } \\
\text { ancestrale, dighoricum, segetale }\end{array}$ & 17 & 97 & $\begin{array}{l}\text { Afghanistan, Azerbaijan, Pakistan, Russia, Spain Sweden, } \\
\text { Turkey, Turkmenistan. }\end{array}$ \\
\hline Cultivated Landraces & S. cereale subsp. cereale & 48 & 275 & $\begin{array}{l}\text { Afghanistan, Austria, Belarus, Bosnia, Czech Republic, } \\
\text { Finland, France, Germany, Greece, Hungary, Italy, } \\
\text { Montenegro, Morocco, Norway, Poland, Portugal, } \\
\text { Romania, Russia, Scotland, Spain, Sweden, Switzerland, } \\
\text { Tajikistan, Turkey, Ukraine. }\end{array}$ \\
\hline $\begin{array}{l}\text { Cultivated elite } \\
\text { breeds }\end{array}$ & S. cereale subsp. cereale & 3 & 18 & Germany, Sweden, USA. \\
\hline
\end{tabular}

Accessions were provided by the following genebanks with acronym, accession prefix and country indicated: United States Department of Agriculture Germplasm Resources Information Network (GRIN, PI, USA), Leibniz-Institut für Pflanzengenetik und Kulturpflanzenforschung (IPK, R, Germany), Nordic Genetic Resource Center (NordGen, NGB, Sweden), Instytut Hodowli i Aklimatyzacji Roślin (IHAR, PL, Poland), Institut National de Recherche Agronomique (INRA, INRA, France), Science and Advice for Scottish Agriculture (SASA, SASA, Scotland). One accession (KENO004) was collected 'on farm' in 2012 (Annika Michelsson, pers. com.). The panel included cultivated rye landraces, cultivated elite breeds ('Imperial', 'Kungs II' and 'Petkus'), feral rye (S. cereale subsp. afghanicum, ancestrale, dighoricum and segetale; henceforth referred to by their sub-specific classification) and wild ryes (S. strictum, S. africanum, $S$. vavilovii) (Table 1 and Additional file 1). Accessions for which passport data regarding growth habit (winter vs spring) were lacking were test cultivated in a greenhouse. Accessions that flowered and produced ears within less than two months without vernalization were considered to be of spring habit, while those that had not flowered were considered to be of winter habit. DNA was extracted from young leaves of 6 individual plants of each accession using the DNeasy Plant Mini Kit (Qiagen, Hilden, Germany) or the E.Z.N.A Plant DNA kit (Omega Biotek Inc., Norcross, GA, US).

\section{SNP genotyping}

Genotyping was performed using the Illumina Golden Gate assay at the SNP\&SEQ Technology Platform at Uppsala University, Sweden. A panel of 768 SNPs were genotyped following the service provider's protocol. The SNPs assayed were chosen from a panel developed by Haseneyer et al. [36] (Additional file 2). Due to lack of mapping information at the time, SNPs were selected to represent different biological roles, as described in their annotation. Later obtained mapping information [38] for
100 of the SNPs showed an even distribution among chromosomes. SNPs not fulfilling Illumina Golden Gate design recommendations were avoided. Results were analyzed using the software GenomeStudio 2011.1 (Illumina).

\section{Chloroplast SSR genotyping}

The rye plants screened for the SNP panel were also genotyped with five chloroplast SSRs (cpSSRs) (Wct2, Wct12, Wct13, Wct15, Wct22), developed for Lolium and wheat but applicable to rye $[39,40]$. The forward primer of the cPSSR markers was labelled with either of two fluorescent dyes: 6-FAM or HEX and PCR products were analysed on an ABI PRISM ${ }^{\circ} 3730$ DNA Analyser at NTNU (Trondheim, Norway). Chromatograms were analysed using GeneMapper 3.7 software with alleles scored using the binning function.

\section{Data analysis}

Accessions were grouped on the basis of taxon, biological type (ie: wild, feral and cultivated) and geographic provenance of cultivated landraces. The latter was based on the four agro-climatic zones proposed by Bouma [41]: Maritime, Mediterranean, Central and North East. Five accessions located outside of the region studied by Bouma were excluded from analyses of agro-climatic zones.

Allele frequencies and genetic diversity measures were calculated using PowerMarker 3.25 [42] and GenAlEx 6.5 [43]. These measures included expected (under Hardy-Weinberg equilibrium) and observed heterozygosity $\left(\mathrm{H}_{\mathrm{E}}\right.$ and $\left.\mathrm{H}_{\mathrm{O}}\right)$, number of alleles and inbreeding coefficient (fixation index, F). Measures were calculated both within each accession, and across all accessions within the groups of taxon, biological type and agroclimatic zone respectively. To evaluate the effects of ascertainment bias genetic diversity was also calculated for haplotypes of length two to five SNPs. Based on mapping data [38] SNPs with a known mapping position were merged into haplotypes consisting of two to five 
neighbouring SNPs, which were then used for diversity calculations.

Pairwise genetic and geographic distances between accessions and pairwise $\mathrm{F}_{\mathrm{ST}}$ between different groups as well as AMOVAs were calculated using GenAlEx 6.5, using 999 permutations for testing variance components. To investigate Isolation-by-Distance we used GenAlEx 6.5 to compute a Mantel test (using 999 permutations) for correlation between a genetic distance matrix and a geographic distance matrix for cultivated rye landraces. To assess whether rye cultivation spread in a slow stepwise fashion with few individuals migrating to new areas from previous populations starting in an original core area (assumed to be Turkey $[14,17])$, we plotted the genetic diversity $\left(\mathrm{H}_{\mathrm{E}}\right)$ of each landrace against its distance to origin as well as latitude and longitude.

Population structure in our Secale accession panel was investigated using the Bayesian model-based approach implemented in the STRUCTURE 2.3.4 software [44]. The program was run with values of $K$ ranging from 1 to 12 , with 20,000 burn-in iterations and 50,000 MCMCs, with 10 independent runs for each $\mathrm{K}$, using the admixture model with correlated allele frequencies. The most likely value of $\mathrm{K}$ was evaluated from the CLUMPP $\mathrm{H}^{\prime}$ values [45] and $\Delta K$ according to the Evanno et al. [46] method. STRUCTURE was run for the complete dataset and for subsets of accessions to infer structure within taxonomic groups, within clusters detected during the analysis of the full data set and within geographical areas. R 3.0.2 [47] was used for evaluating CPSSR markers for population structure with discriminant analysis of principal components (DAPC) using the adegenet package [48]. Clusters for the analysis of cultivated rye were mapped in ArcGIS 10.0 (ESRA).

Principal Component Analysis (PCA) was also computed with the $\mathrm{R}$ environment for statistical computing for the complete accession panel and for different subsets of cultivated rye. Computation of PCA was based on a matrix of allele frequencies for each accession at each locus. The data from the PCA was further used to generate a relative measure of genetic relatedness within accessions, PC dispersion [34]. This measure, calculated in $\mathrm{R}$, utilizes mean pair-wise distances in the PC-space between individuals belonging to the same accessions. Information from all principal components was included as multidimensional coordinates.

To compare the effects of analysing genetic diversity based on multiple samples of the same accessions with that based on pooled samples we carried out in silico pooling of our accessions. In the in silico pooling we assumed that each individual rye extraction contributed equally to the genotype scoring of the pool, which would be the ideal case if equal molar amounts of DNA were added from each extraction. We then chose an ad hoc cut-off point of 0.75 to create an interpretation reflecting the SNP scoring procedure and limiting the loss of information. Each accession was assigned a heterozygous genotype if the allele frequency of the more common allele was less than 0.75 . If the more common allele was present in the accession at higher frequencies than 0.75 the accession was assigned a homozygous genotype. The resulting accession genotypes were used for diversity and structure analyses as described above.

\section{Results}

\section{Genotyping success}

We genotyped 468 individuals from 80 accessions for a total of 768 SNP markers. Although we aimed to analyse six individuals per accession, in some instances, due to low DNA quality or to make room for positive and negative controls in 96-well plates, some samples had to be excluded and only five individuals were analysed for some accessions. Of the 768 SNPs assayed 134 failed to produce genotyping results. An additional 32 markers failed in more than $50 \%$ of the individuals screened and 35 proved to be monomorphic. All these 201 markers were thus removed from the dataset before further analysis. Of the 468 individuals initially screened, 11 failed to produce reliable calls for any marker and 5 had too many missing data points and were removed before further analysis. Two accessions were also removed for containing data from less than four individuals. Additionally, two S. strictum accessions (PI 240285 and PI 531829, 12 individuals) were excluded after doubts about their taxonomic classification (see further below). After the exclusion of markers and individuals, a final dataset consisting of 567 SNPs screened in 434 individual plants belonging to 76 accessions were used for further analysis.

Among the 567 SNPs analysed for the 434 individuals in the final dataset a $95 \%$ genotype scoring success was obtained. Although initially developed for cultivated rye elite varieties, the SNP panel worked efficiently for all taxa, with $S$. afghanicum and S. segetale having the lowest proportion of missing data $(2.73 \%$ and $3.62 \%$ respectively) and the wild ryes $S$. strictum and $S$. africanum having the highest ( $8.82 \%$ and $5.76 \%$ respectively).

\section{Genetic diversity}

Both alleles of most of the biallelic markers could be found in all three groups of biological types, wild (average 1.974 alleles per marker), feral (average 1.993 alleles per marker) and cultivated (both alleles found in all markers) as well as in the different taxa ( $\mathrm{Na}$ in Table 2). Looking within accessions, however, monomorphic markers were more common in the wild and feral accessions than in cultivated accessions. With the exception of $S$. africanum minor allele frequencies were fairly evenly distributed (Additional file 3 ). Total genetic diversity $\mathrm{H}_{\mathrm{E}}$ was highest 
Table 2 Summary of genetic diversity measures for the complete accession panel and selected subgroups based on 567 polymorphic SNPs. Both within accession averages and total diversity within groups are shown as well as diversity upon sample pooling in silico. N: sample size - number of accessions (number of individuals within brackets); Na: number of alleles; $\mathrm{H}_{\mathrm{O}}$ : Observed Heterozygosity; $\mathrm{H}_{\mathrm{E}}$ : Expected Heterozygosity; F: Fixation Index

\begin{tabular}{|c|c|c|c|c|c|c|}
\hline Group & & $N$ & $\mathrm{Na}$ & $H_{O}$ & $H_{E}$ & $F$ \\
\hline \multicolumn{7}{|l|}{ Biological type } \\
\hline \multirow[t]{3}{*}{ Wild } & Within acc. & $8(44)$ & 1.526 & 0.214 & 0.187 & -0.151 \\
\hline & In silico pooled & & 1.825 & 0.240 & 0.256 & 0.028 \\
\hline & Total & & 1.974 & 0.224 & 0.286 & 0.178 \\
\hline \multirow[t]{3}{*}{ Feral } & Within acc. & $17(97)$ & 1.675 & 0.257 & 0.241 & -0.078 \\
\hline & In silico pooled & & 1.952 & 0.309 & 0.294 & -0.032 \\
\hline & Total & & 1.993 & 0.259 & 0.329 & 0.206 \\
\hline \multirow[t]{3}{*}{ Cultivated } & Within acc. & $51(290)$ & 1.777 & 0.316 & 0.283 & -0.114 \\
\hline & In silico pooled & & 1.977 & 0.375 & 0.309 & -0.162 \\
\hline & Total & & 2.000 & 0.313 & 0.347 & 0.096 \\
\hline \multicolumn{7}{|l|}{ Taxon } \\
\hline \multirow[t]{3}{*}{ S. africanum } & Within acc. & $1(6)$ & 1.568 & 0.215 & 0.188 & -0.131 \\
\hline & In silico pooled & & 1.220 & 0.220 & 0.110 & -1.000 \\
\hline & Total & & 1.568 & 0.215 & 0.188 & -0.131 \\
\hline \multirow[t]{3}{*}{ S. strictum } & Within acc. & $4(20)$ & 1.317 & 0.134 & 0.114 & -0.172 \\
\hline & In silico pooled & & 1.429 & 0.158 & 0.144 & -0.113 \\
\hline & Total & & 1.568 & 0.135 & 0.152 & 0.083 \\
\hline \multirow[t]{3}{*}{ S. vavilovii } & Within acc. & $3(18)$ & 1.790 & 0.321 & 0.284 & -0.128 \\
\hline & In silico pooled & & 1.686 & 0.356 & 0.262 & -0.325 \\
\hline & Total & & 1.949 & 0.322 & 0.327 & 0.009 \\
\hline \multirow[t]{3}{*}{ S. afghanicum } & Within acc. & $4(21)$ & 1.666 & 0.254 & 0.242 & -0.067 \\
\hline & In silico pooled & & 1.693 & 0.312 & 0.250 & -0.223 \\
\hline & Total & & 1.903 & 0.254 & 0.297 & 0.124 \\
\hline \multirow[t]{3}{*}{ S. ancestrale } & Within acc. & $5(30)$ & 1.707 & 0.267 & 0.243 & -0.100 \\
\hline & In silico pooled & & 1.725 & 0.292 & 0.244 & -0.177 \\
\hline & Total & & 1.963 & 0.268 & 0.301 & 0.092 \\
\hline \multirow[t]{3}{*}{ S. dighoricum } & Within acc. & $4(23)$ & 1.639 & 0.231 & 0.229 & -0.026 \\
\hline & In silico pooled & & 1.771 & 0.311 & 0.276 & -0.129 \\
\hline & Total & & 1.938 & 0.235 & 0.310 & 0.218 \\
\hline \multirow[t]{3}{*}{ S. segetale } & Within acc. & $4(23)$ & 1.680 & 0.274 & 0.249 & -0.113 \\
\hline & In silico pooled & & 1.741 & 0.324 & 0.274 & -0.166 \\
\hline & Total & & 1.944 & 0.278 & 0.322 & 0.118 \\
\hline \multirow[t]{3}{*}{ S. cereale } & Within acc. & $51(290)$ & 1.777 & 0.316 & 0.283 & -0.114 \\
\hline & In silico pooled & & 1.977 & 0.375 & 0.309 & -0.162 \\
\hline & Total & & 2.000 & 0.313 & 0.347 & 0.096 \\
\hline \multicolumn{7}{|c|}{ Geographical provenance $^{a}$} \\
\hline \multirow[t]{3}{*}{ Central } & Within acc. & $6(35)$ & 1.738 & 0.304 & 0.271 & -0.123 \\
\hline & In silico pooled & & 1.838 & 0.374 & 0.299 & -0.217 \\
\hline & Total & & 1.981 & 0.304 & 0.338 & 0.088 \\
\hline \multirow[t]{3}{*}{ Maritime } & Within acc. & $14(79)$ & 1.780 & 0.329 & 0.285 & -0.144 \\
\hline & In silico pooled & & 1.910 & 0.392 & 0.307 & -0.225 \\
\hline & Total & & 1.989 & 0.327 & 0.344 & 0.047 \\
\hline
\end{tabular}


Table 2 Summary of genetic diversity measures for the complete accession panel and selected subgroups based on 567 polymorphic SNPs. Both within accession averages and total diversity within groups are shown as well as diversity upon sample pooling in silico. N: sample size - number of accessions (number of individuals within brackets); Na: number of alleles; $\mathrm{H}_{\mathrm{O}}$ : Observed Heterozygosity; $\mathrm{H}_{\mathrm{E}}$ : Expected Heterozygosity; F: Fixation Index (Continued)

\begin{tabular}{|c|c|c|c|c|c|c|}
\hline \multirow[t]{3}{*}{ Mediterranean } & Within acc. & $15(86)$ & 1.785 & 0.315 & 0.285 & -0.103 \\
\hline & In silico pooled & & 1.924 & 0.380 & 0.301 & -0.209 \\
\hline & Total & & 1.993 & 0.314 & 0.343 & 0.084 \\
\hline \multirow[t]{3}{*}{ North East } & Within acc. & $8(43)$ & 1.814 & 0.322 & 0.294 & -0.095 \\
\hline & In silico pooled & & 1.788 & 0.374 & 0.270 & -0.315 \\
\hline & Total & & 1.988 & 0.321 & 0.333 & 0.032 \\
\hline
\end{tabular}

${ }^{\mathrm{a} F o r}$ landrace rye only. Based on Bouma's [41] proposed agro-climatic zones

in cultivated rye and lowest in wild (Table 2). The taxon with the highest $\mathrm{H}_{\mathrm{E}}$ was $S$. cereale, likely an effect of ascertainment bias during the SNP discovery (see below), followed by S. vavilovii and S. segetale. S. strictum and $S$. africanum had the lowest $\mathrm{H}_{\mathrm{E}}$ (Table 2). Differences in total genetic diversity between geographical groups of cultivated rye were very small. Inbreeding coefficients (F) were in general low as could be expected from an outcrossing species (Table 2). However, notably, some taxa (e.g. S. dighoricum) have higher inbreeding coefficients than others, possibly indicating more limited geneflow within this taxon or higher rates of self-pollination. Likewise, among geographical groups of cultivated landraces, inbreeding coefficients are somewhat higher in the Central and Mediterranean groups than in the North East and Maritime groups (Table 2).

Average within-accession diversity for groups was just somewhat lower than total diversity, showing that most diversity is captured within accessions, and to a lesser extent distributed between accessions. Differences in average within-accession $\mathrm{H}_{\mathrm{E}}$ are statistically significant both comparing biological type and taxa (two-way ANOVA, both $P<0.001)$. Among cultivated rye landraces from different regions, differences in genetic diversity, $\mathrm{H}_{\mathrm{E}}$, were small and non-significant (one-way ANOVA, $P=0.16)$. In silico pooling of accession genotypes showed that a genotyping strategy of pooled individuals would have in general captured between 80 and $94 \%$ of the genetic diversity of the accessions (Table 2). No significant differences in inbreeding coefficients (F) for accessions were found among biological types $(P=$ $0.06)$, taxa $(P=0.54)$ or geographical regions $(P=0.44)$. Looking at single accessions, within-accession diversity was lowest in the two S. strictums PI 401405 (0.092) and PI 401399 (0.090) while the highest within-accession diversity was detected in the Swedish landrace NGB21083 (0.313) and the S. segetale accession PI 326284 (0.314) (Additional file 1). Within-accession $\mathrm{H}_{\mathrm{E}}$ was not significantly lower in commercial cultivars than in landraces $(t$-test, $P=0.56)$.
In conclusion we find high diversity levels within single accessions and increasing diversity levels going from wild to feral to domesticated rye. Ascertainment bias could be a possible cause for the differences in diversity between different biological types. When the distribution of minor allele frequencies of the marker were compared with the distribution expected under neutrality the presence of ascertainment bias was clear from the deficit of low frequency alleles and the excess of higher frequency alleles (Additional file 4). However, also the wild and feral rye, not part of the material used to ascertain the SNPs showed a clear deficit of lower frequency alleles suggesting that the effects of ascertainment bias were not substantially different between the three types of material (Additional file 4). To further evaluate the effects of ascertainment bias on the estimate of genetic diversity we merged SNPs that had been mapped to neighbouring positions into haplotypes consisting of two to five neighbouring SNPs. Such merging of SNPs into haplotypes has previously been shown to alleviate the effects of ascertainment bias [49]. Merging SNPs into increasingly long haplotypes had little effect on the relative ranking of the different rye taxa and $S$. strictum and $S$. africanum were still the least diverse taxa when merging SNPs into 5-SNP haplotypes (Fig. 1a). With large amounts of ascertainment bias the relative diversity of the different taxa should become more similar with increasing haplotype length. Compared to the diversity in $S$. cereale most taxa showed a limited such increase (less than $10 \%$ for S. afghanicum, S. ancestrale, S. dighoricum, S. segetale and S. vavilovii). S. africanum (12\% increase) and S. strictum (28\% increase) did, however, show a clear increase in diversity relative to $S$. cereale (Fig. 1b).

The distribution of genetic diversity between and within different taxa and biological types was analysed using AMOVA (Table 3). As ascertainment bias is likely to bias the partitioning of molecular variation [50] S. africanum and S. strictum accessions were excluded from the AMOVA. The AMOVA results 


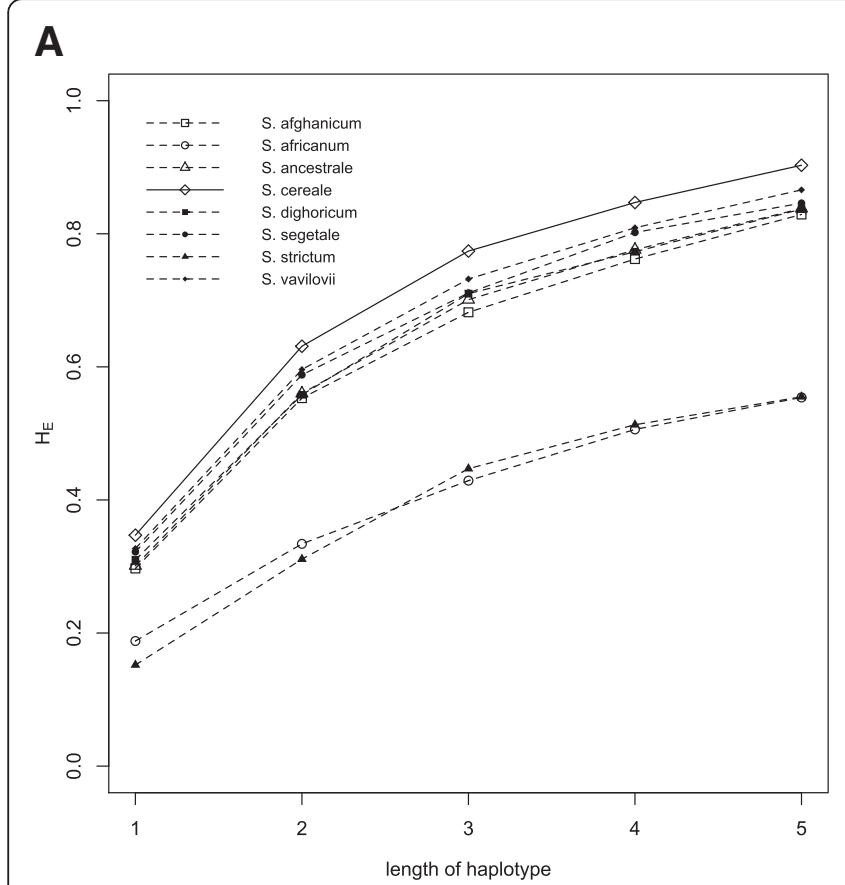

B

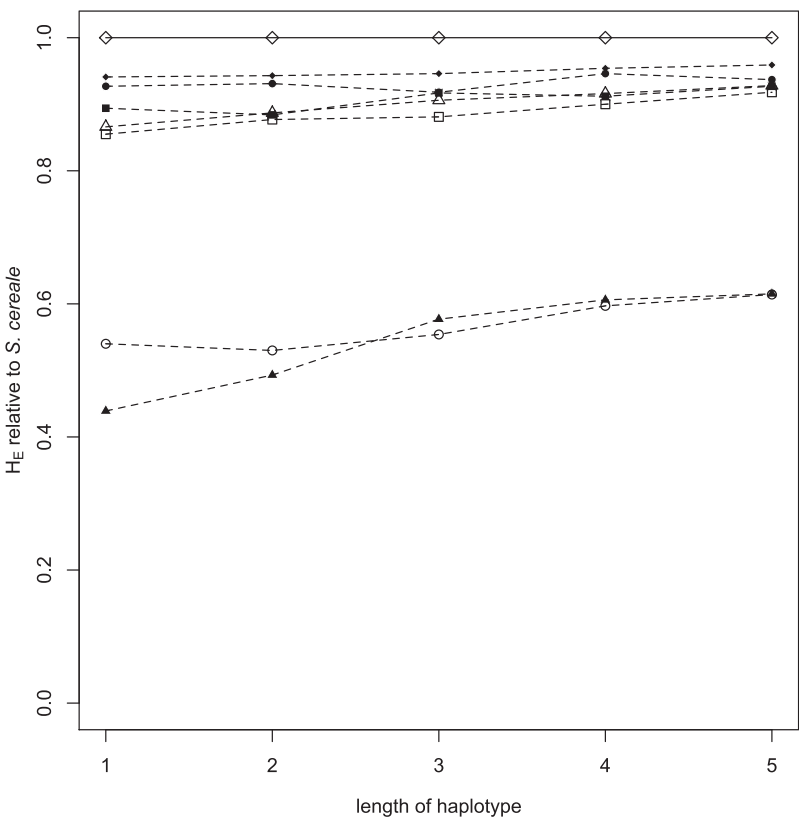

Fig. 1 Genetic diversity of the different taxa studied for individual SNPs and neighbouring SNPs merged into haplotypes of length $2-5$ SNPS. a Genetic diversity $\left(H_{E}\right)$. b) Genetic diversity relative to the diversity of $S$. cereale

confirmed that diversity was primarily found within accessions. Among taxa, $3 \%$ of the diversity was found, among types (wild vs feral vs cultivated) only $1 \%$ of the diversity and among cultivated rye from different agro-climatic zones, $1 \%$ of the diversity was found between regions. The large proportion of diversity found within accessions for all three types of groupings suggests high gene flow between different accessions, reflecting the wind-pollinated reproduction of rye.

Table 3 Analysis of molecular variance (AMOVA) for 405 individuals, 71 accessions, six taxa, three biological types and four geographic regions

\begin{tabular}{|c|c|c|c|c|}
\hline Group & $\mathrm{df}$ & SS & Variance component & $\%$ of the total variance \\
\hline \multicolumn{5}{|l|}{ Biological type $^{a}$} \\
\hline Among Type & 2 & 1022.300 & 1.442 & $1 \%$ \\
\hline Among Accessions & 68 & 17417.886 & 14.576 & $14 \%$ \\
\hline Within Accessions & 739 & 66529.167 & 90.026 & $85 \%$ \\
\hline Total & 809 & 84969.353 & 106.044 & $100 \%$ \\
\hline \multicolumn{5}{|l|}{$\operatorname{Taxon}^{\mathrm{a}}$} \\
\hline Among Taxa & 5 & 2278.843 & 2.684 & $3 \%$ \\
\hline Among Accessions & 65 & 16160.593 & 13.919 & $13 \%$ \\
\hline Within Accessions & 739 & 66529.167 & 90.026 & $84 \%$ \\
\hline Total & 809 & 84968.602 & 106.629 & $100 \%$ \\
\hline \multicolumn{5}{|c|}{ Geographical provenance $^{\mathrm{b}}$} \\
\hline Among Regions & 3 & 1012.993 & 0.977 & $1 \%$ \\
\hline Among Accessions & 39 & 8691.992 & 11.403 & $11 \%$ \\
\hline Within Accessions & 443 & 41691.525 & 94.112 & $88 \%$ \\
\hline Total & 485 & 51396.510 & 106.492 & $100 \%$ \\
\hline
\end{tabular}

df: degrees of freedom; SS: sum of squares

${ }^{a}$ Excluding $S$. africanum and $S$. strictum accessions

${ }^{\mathrm{b}}$ For landrace rye only. Based on Bouma's [41] proposed agro-climatic zones 


\section{Population structure}

We investigated our data for genetic structure by initially running STRUCTURE for the full final data set. The values of $\triangle K$ and CLUMPP $\mathrm{H}^{\prime}$ indicated $K=2,3$ and 9 as the models best describing genetic structure in our rye accessions (Additional file 5). From the Q-matrix plots the presence of admixture could be seen, as different individuals within the same accession sometimes showed membership to several different clusters (Additional file 6). The first clusters STRUCTURE detected $(K=2)$ were one comprising some of the wild S. strictum accessions plus the accession of $S$. africanum (dark green in Additional file 6), and a second containing all cultivated and feral rye accessions as well as the wild rye $S$. vavilovii. The $S$. strictum - africanum cluster remained intact while increasing $K$ to the value of 12 (Additional file 6). At $K=2$ we noted that two accessions labelled as S. strictum (PI 240285 and PI 531829) did not cluster with S. africanum and the other $S$. strictum accessions but rather with the remaining rye. This observation and inspection of spike morphology, not showing the disarticulating rachis significant for S. strictum [10], cast doubts about them being de facto S. strictum. We therefore decided to exclude them from all analyses where taxonomic status was relevant.

At $K=3$, the $S$. strictum and $S$. africanum cluster remained intact (Additional file 6). The other cluster was split in two with the new clusters mainly reflecting a geographical division between accessions from Asia and Europe. S. cerale landraces from Asia (left side of S. cereale panel) showed the highest similarity to most of the feral ryes originating from the same region. Landraces from Western Europe also showed a degree of clustering with these ryes, while landraces from Italy, Eastern and Northern Europe clustered together at a high degree.

When the model $K=9$ is considered, five clusters were observed within the cultivated rye (Fig. 2a). These five clusters largely reflected geographic origin. One cluster consisted mainly of accessions from Northern Europe (yellow in Fig. 2a), a second cluster (dark blue) included cultivated rye accessions mostly from the west but also from Switzerland and Turkey as well as an accession of S. vavilovii from Italy, a third cluster is prevalent in Central Europe (red cluster). Accessions from the Balkans and Asia were found a fourth cluster (turquoise). The last cluster (pink) consisted of two accessions from a limited area, Finnmarken, on the border between Norway and Sweden. At low levels of $K$ these individuals clustered with other Fennoscandian and Eastern European accessions. However, already at $K=5$ they were beginning to separate from other Fennoscandian ryes and at $K=7$ they were forming a cluster distinct from all other ryes (Additional file 6).

At the $K=9$ level the accessions in some of the feral ryes, such as $S$. ancestrale and $S$. afghanicum showed fairly consistent clustering while others such as $S$. vavilovii, S. dighoricum and S. segetale showed a mixed clustering. It is worth noting that the accessions of $S$. ancestrale and $S$. afghanicum had a much less widespread origin than the accessions in the other three taxa. For example, the S. ancestrale accession PI 283971 with an origin assigned to Algeria clustered apart from the remaining $S$. ancestrale accessions with origins in Turkey and Turkmenistan. The three breeds included in the analysis did not cluster separately from landraces, but were split on different cluster groups, partly reflecting their geographical origin.

In order to confirm the general clustering and investigate substructure within the clusters detected we ran STRUCTURE with different subsets of accessions. When STRUCTURE was run excluding the $S$. strictum and $S$. africanum accessions the population structure of the remaining accessions was maintained as in the full set of accessions (data not shown). Analysis of only wild and feral accessions had the highest support for $K=4$ (though with high support also for $K=2$ and 3) (Additional file 5, Fig. 2b). At this level S. africanum and S. strictum clustered separately from S. vavilovii and the feral ryes. The other ryes all had accessions clustering together (dark blue in Fig. 2b) but with some accessions among S. afghanicum and $S$. ancestrale showing clustering similar to the one detected in the full dataset at $K=9$. The geographic clustering observed among feral rye accessions in the full dataset was less evident when the structuring could not be anchored to the one among domesticated S. cereale. However, the geographically distant S. segetale R 1039 from Pakistan clustered with some of the S. afghanicum (only growing in Afghanistan) accessions rather than with the remaining $S$. segetale.

When only cultivated landrace rye was analysed both $\triangle K$ and CLUMPP $\mathrm{H}^{\prime}$ values suggested $K=2$ and $K=5$ as the models with the highest support (Additional file 5). At $K=5$ the main clusters observed agreed with the ones detected for the complete data set at $K=9$ (Fig. 2c). The genetic structure detected was clearly geographically distributed, but showed limited overlap with the major agro-climatic zones proposed by Bouma [41] (Fig. 3). For example Southern Scandinavian accessions clustered with North Eastern accessions rather than maritime ones as suggested by its agro-climate. Additionally, Iberian and North African accessions showed little clustering with other accessions from the Maritime zone. We noted that accessions primarily belonging to the blue cluster in Western Europe and North Africa have spring habit and accessions belonging to the yellow and pink cluster in Northern Europe have winter growth habit. The other clusters, with accessions from Central Europe and the Mediterranean include both spring and winter types. 
PCA confirmed that the S. africanum and the S. strictum accessions differed genetically from both the feral and cultivated rye (bottom-left quadrant in Fig. 4). PC1 showed a very clear distinction between the $S$. africanum
- S. strictum and the S. cereale subspecies. In the cluster of $S$. cereale subspecies, $S$. ancestrale showed the clearest grouping whereas other subspecies proved to be more genetically diverse (Fig. 4). Cultivated rye accessions

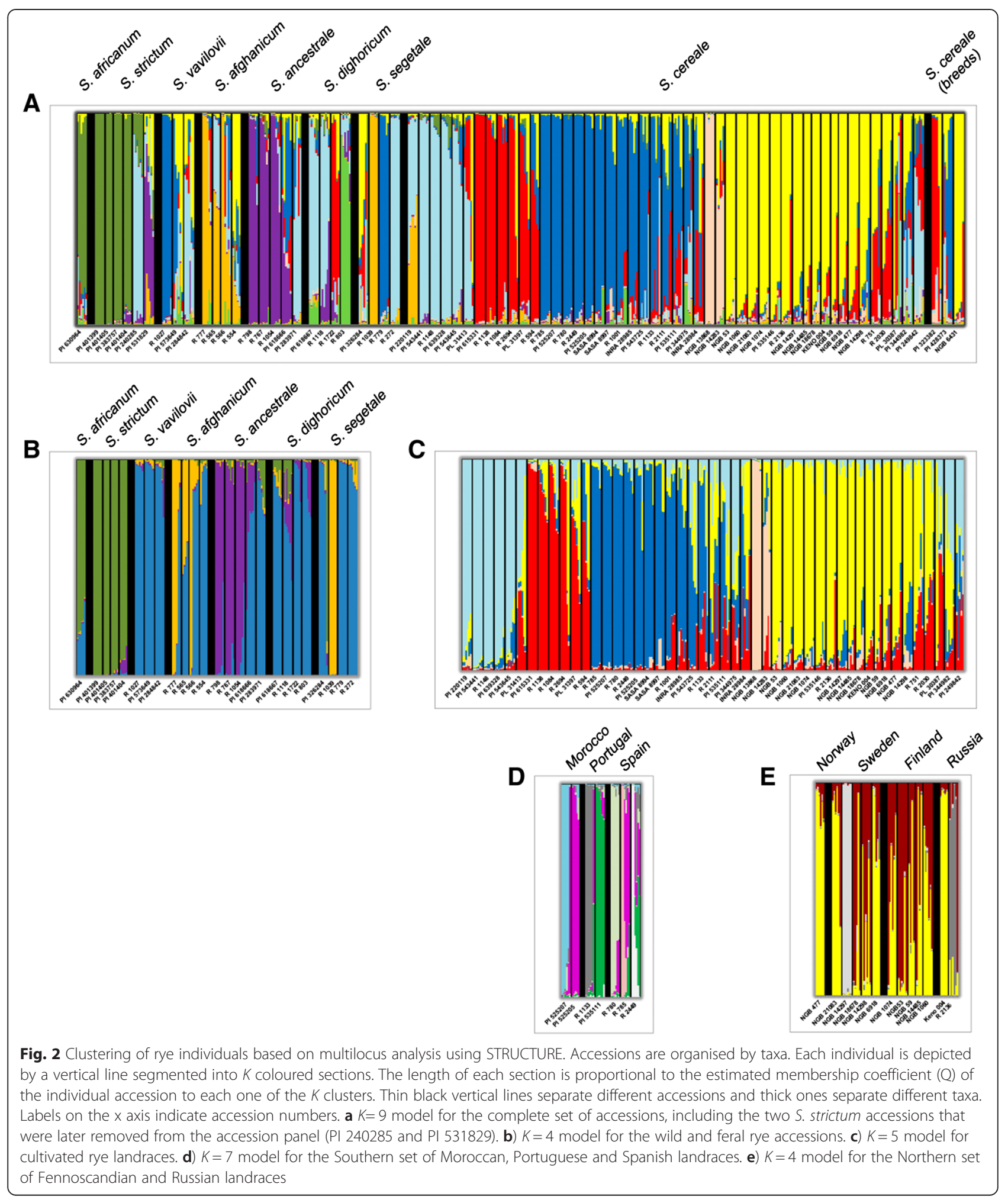




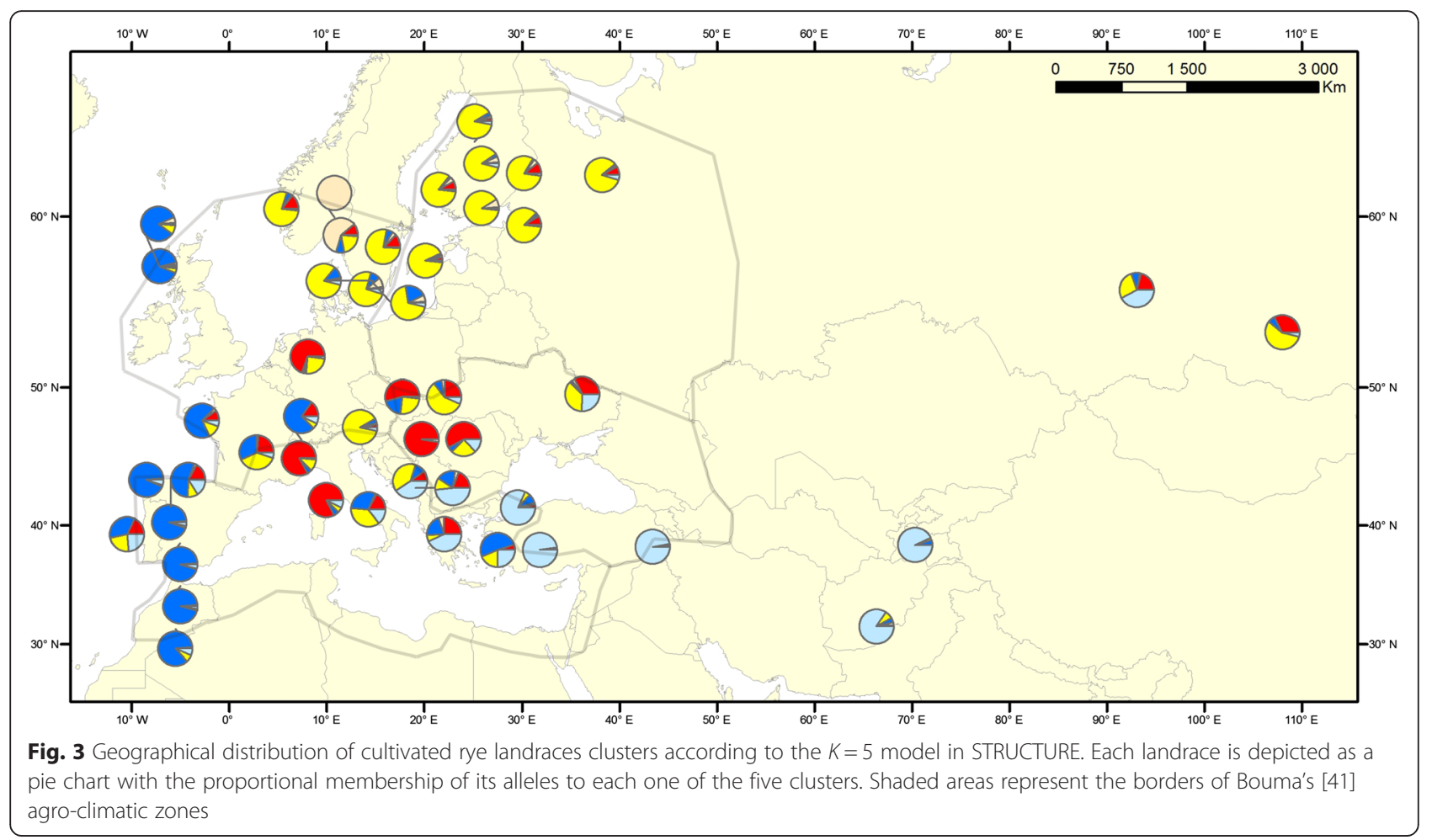

from areas with rye growing feral tended to be located close to the feral ryes rather than other cultivated rye. For example, accessions R 272 and R 1039 (S. segetale) and R 566, R 565 and R 777 (S. afghanicum) clustered around PI 220119 (landrace from Afghanistan, top-right quadrant). Accessions R 779 (S. segetale) from Spain and R 1027 (S. vavilovii) from Italy clustered closely with the cultivated Spanish landraces R 2449, R 785 and R 780 and the Moroccan landraces PI 525205 and PI 525207 (top-right quadrant) (Fig. 4). Focusing on the cultivated rye only, there was some agro-climatic clustering based on the zones of Bouma et al. [41], but with clear overlap and outliers (Fig. 5), as observed in the STRUCTURE analysis (Fig. 3). The North East group was clearly separated from the Mediterranean and Central group, but overlapped the Maritime group. However, all accessions in the Maritime group clustering with the North East group had Scandinavian origin.

We also calculated PC dispersion as a measure of the within-accession spread of individuals in the PC space (Additional file 1). Wild ryes in general showed less dispersion, that is were more homogenous, than both feral and cultivated rye (two-way ANOVA, $P<0.001$ ) but there was no difference between feral and cultivated ryes. Among taxa, S. strictum accessions had lower PC dispersion than $S$. cereale accessions $(P<0.05)$ and $S$. vavilovii had higher PC dispersion than $S$. ancestrale $(P<0.05), S$. cereale $(P<0.01)$ and $S$. strictum $(P<0.01)$, but no other groups of ryes differed in $\mathrm{PC}$ dispersion. The landrace accession NGB477 had a PC dispersion clearly lower than all other $S$. cereale accessions. Interestingly, the S. africanum accession that clustered together with S. strictum in the STRUCTURE analysis did not show a deflated PC dispersion.

From the PC dispersion measures, some $S$. cereale accessions showed inflated variance. This drew our attention to a few individuals that were genetically identical or highly similar, thus reducing the perceived genetic diversity of those accessions. Removing these individuals had no statistically significant effect on neither genetic diversity indices, pairwise $\mathrm{F}_{\mathrm{ST}}$ or genetic distances (all $P>0.05$, two-tailed $t$-test). We thus concluded that the presence of highly similar or identical individuals had a negligible effect on diversity measures.

Pairwise $\mathrm{F}_{\mathrm{ST}}$ values were calculated between all pairs of taxa (Table 4). The highest $\mathrm{F}_{\mathrm{ST}}$ was observed between S. strictum and S. afghanicum (0.298) and the lowest between $S$. vavilovii and $S$. cereale $(0.016)$. The same taxa also had the highest and lowest pairwise genetic distances (0.154 and 0.017 respectively) (Table 4). It should be noted, however, that amongst our three $S$. vavilovii accessions, two originated in Europe. Looking at pairs of accessions the $\mathrm{F}_{\mathrm{ST}}$ values ranged from 0.044 in a within $S$. cereale comparison to 0.329 in a comparison between a $S$. segetale and a $S$. strictum accession (Additional file 7). In general, comparisons including $S$. strictum accessions showed high $\mathrm{F}_{\mathrm{ST}}$ values when compared with other accessions including other S. strictum 


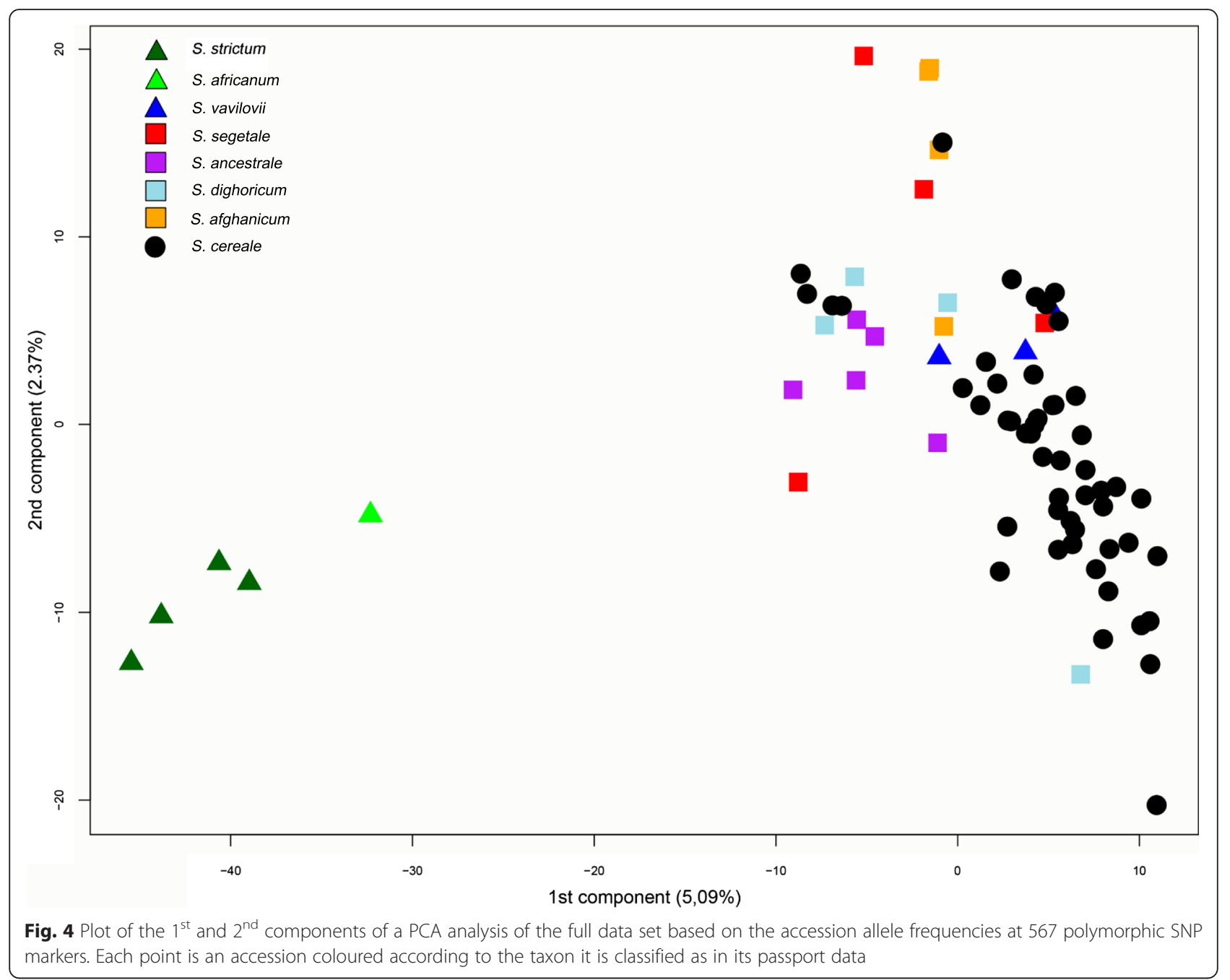

accessions (Additional file 7). Additionally, the rye accessions from Finnmarken (NGB13868 and NGB14283) showed elevated $\mathrm{F}_{\mathrm{ST}}$ values with all other accessions, regardless of taxon, compared to other landrace ryes.

To investigate Isolation-by-Distance we compared the genetic and geographic distances between cultivated rye landraces. No correlation between genetic and geographic distances was found $(\mathrm{R}=0.179 ; P=0.067)$ (Additional file 8$)$. We also plotted genetic diversity against latitude and longitude respectively to see if adaptation to new environments or genetic bottlenecks during spread resulted in populations with reduced diversity. We observed no correlation between genetic diversity and longitude $(\mathrm{R}=0.089 ; P=0.273$ ) (Additional file 9), but a significant correlation between genetic diversity and latitude $(\mathrm{R}=0.387 ; P<0.01)$. Landraces at higher latitudes, contrary to our expectations, proved to be more genetically diverse (Additional file 10). No correlation between genetic diversity and distance to origin could be found ( $R=0.02, P=0.446)$ (Additional file 11). This suggests that diversity was not lost as cultivated rye spread from its centre of origin.

\section{Chloroplast SSRs}

Population structure was also studied using cpSSRs markers. Because of the non-Mendelian inheritance of the markers, we analysed the genetic structure by discriminant analysis of principal components (DAPC), a type of analysis that requires no assumptions of HardyWeinberg equilibrium and is thus more suited for nonnuclear markers than other methods of assessing population structure.

The DAPC analysis of the cpSSR data could not find a distinct number of clusters with high fit. The DIC value showed some tendencies to plateau at $K \approx 4$ and $K \approx 10$ for the full dataset. However, the clustering became 


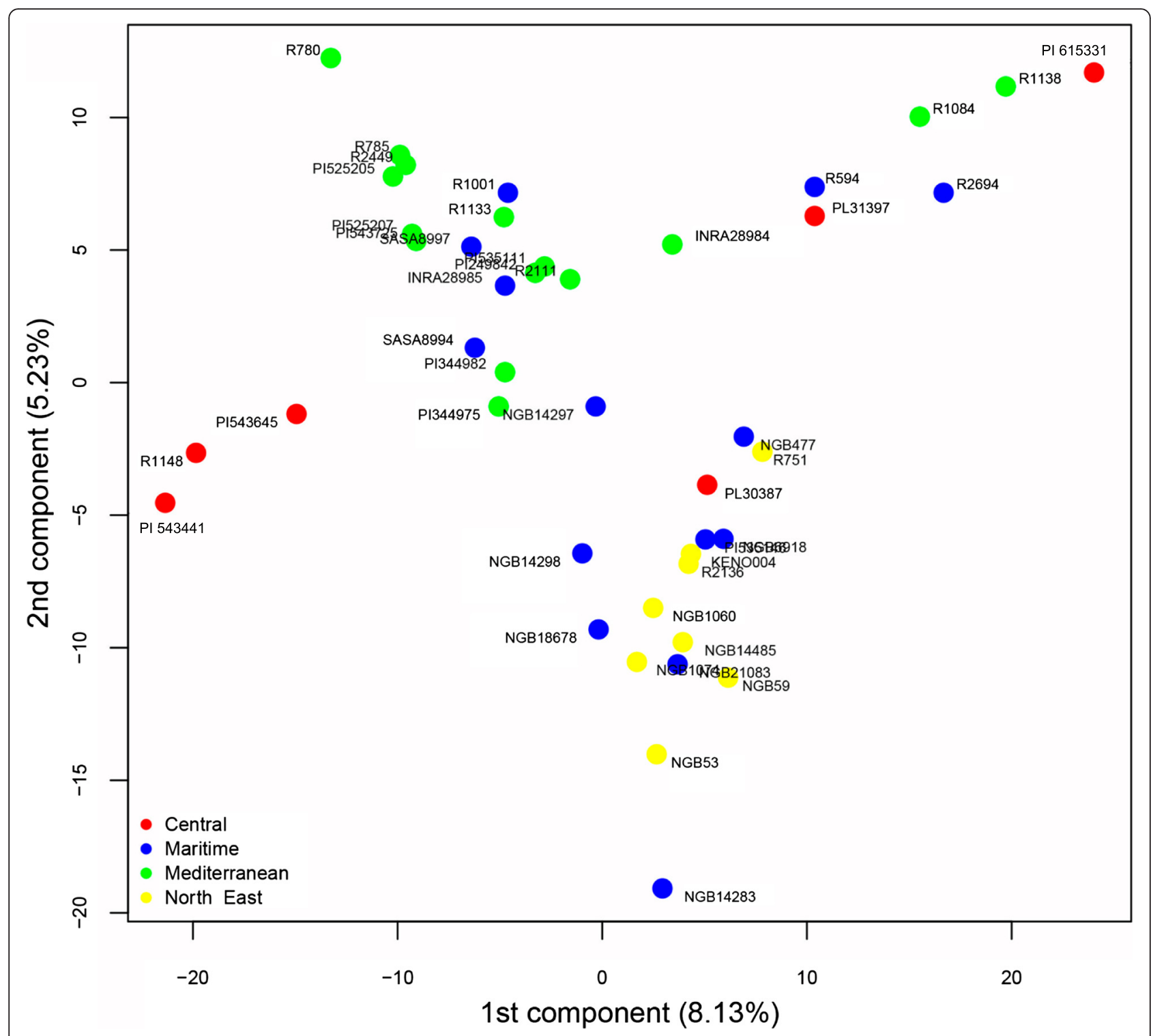

Fig. 5 Plot of the $1^{\text {st }}$ and $2^{\text {nd }}$ components of a PC analysis of the rye landrace accession panel based on the allele frequencies of 567 polymorphic SNP markers. Each point is an accession coloured according to the agro-climatic zone it originates from, as defined by Bouma [41]

Table 4 Pairwise $F_{\text {ST }}$ values (below diagonal) and Nei's pairwise genetic distance (above diagonal) between different taxons based on the allele frequency data for 567 polymorphic SNP markers. For the F ST values, probability ( $\mathrm{P}$ rand $>=$ data), based on 999 pairwise population permutations, is $<0.001$ except $^{\dagger} P=0.003$ and ${ }^{\ddagger} P=0.006$. Correlation between the two matrices is 0.9697

\begin{tabular}{lllllllll}
\hline & S.afghanicum & S.africanum & S.ancestrale & S.cereale & S.dighoricum & S.segetale & S.strictum & S.vavilovii \\
\hline S.afghanicum & - & 0.129 & 0.055 & 0.036 & 0.052 & 0.032 & 0.154 & 0.043 \\
S.africanum & 0.208 & - & 0.110 & 0.124 & 0.119 & 0.116 & 0.051 & 0.131 \\
S.ancestrale & 0.086 & 0.176 & - & 0.032 & 0.040 & 0.043 & 0.123 & 0.044 \\
S.cereale & 0.051 & 0.171 & 0.049 & - & 0.029 & 0.021 & 0.145 & 0.017 \\
S.dighoricum & 0.073 & 0.179 & 0.057 & 0.040 & - & 0.039 & 0.135 & 0.042 \\
S.segetale & 0.041 & 0.176 & 0.062 & 0.025 & 0.048 & - & 0.134 & 0.029 \\
S.strictum & 0.298 & 0.133 & 0.250 & 0.228 & 0.262 & 0.260 & - & 0.151 \\
S.vavilovii & 0.058 & 0.199 & 0.061 & $0.016^{\ddagger}$ & 0.052 & $0.028^{\dagger}$ & 0.286 & - \\
\hline
\end{tabular}




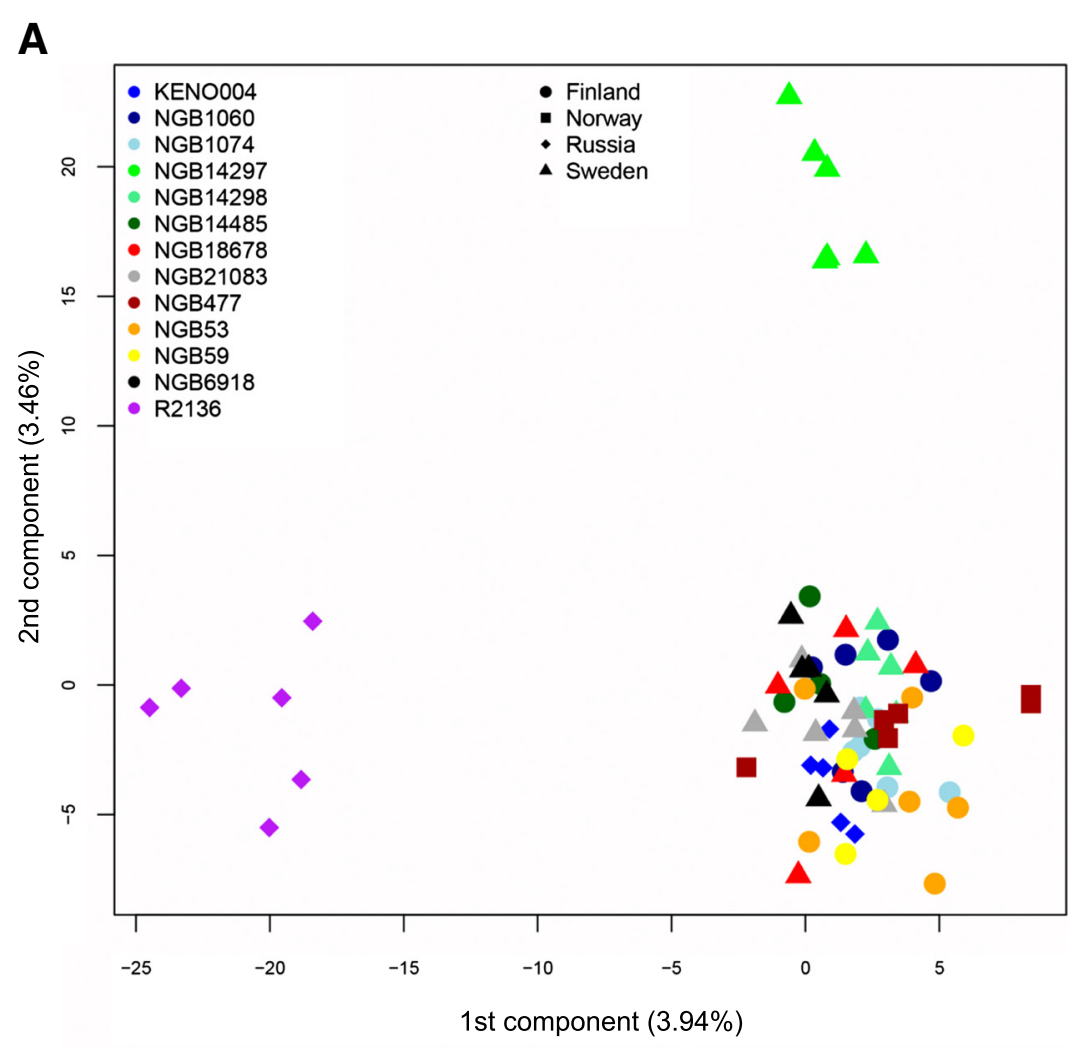

B

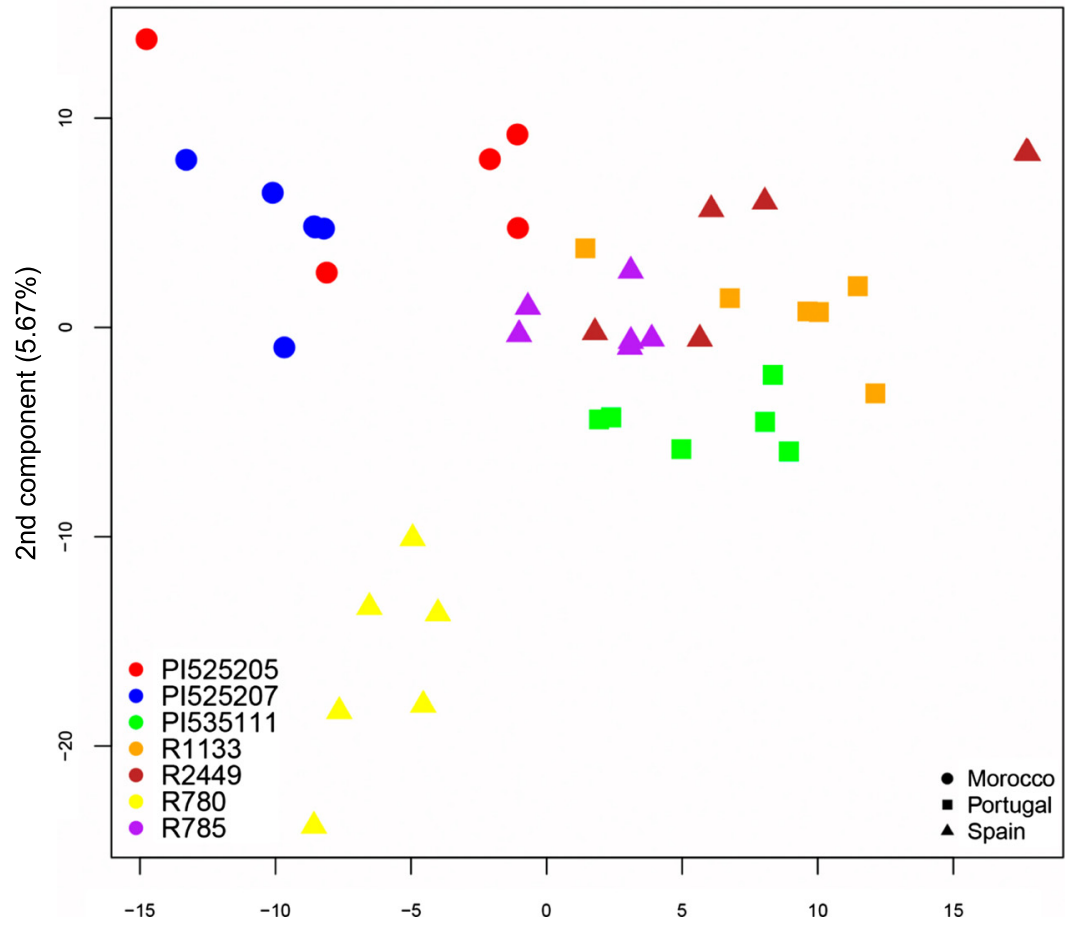

1st component $(6.06 \%)$

Fig. 6 Plot of the $1^{\text {st }}$ and $2^{\text {nd }}$ components of a PCA analysis from contrasting geographic regions. Each point is an individual coloured by accession and shaped according to country of provenance. a Fennoscandian (Finland, Norway and Sweden) and Russian landrace accessions, b) Iberian (Portugal and Spain) and Moroccan accessions 
strongly erratic for $K>3$. DAPC clustering did not reflect biological type or taxonomic groups, with the exception of S. strictum and S. africanum that formed a separate cluster (2). Interestingly, at higher levels of $\mathrm{K}$ the Finnmark accessions NGB13868 and NGB14283 stood out from the rest of the $S$. cereale, much like for the SNP markers, and when studying the full set they frequently clustered together with the $S$. strictum accessions rather than other S. cereale (Additional file 12). When analysing only $S$. cereale accessions the DIC value had a weak plateau at $K=5$, which resulted in a structure reminiscent of the nuclear SNPs, albeit less clear (Additional file 13).

\section{Diversity distribution in areas of contrasting cultivation intensity}

To compare areas where rye has been cultivated with high intensity with areas of much more limited rye cultivation, we analysed additional subsets of landrace rye. The Southern subset consisted of seven accessions from Iberia and Morocco and the Northern subset of fifteen accessions from Fennoscandia and western Russia. Among the Southern accessions results indicated discrete populations with each accession belonging to a distinct cluster with little admixture. With the seven accessions $K=7$ was indeed indicated to be the most likely model (Additional file 5 ). This homogenous clustering of accessions indicated a degree of reproductive isolation (Fig. 2d). In the case of the Northern accessions $K=2$ was the best supported model (Additional file 5). As expected, one cluster consisted of the previously identified individuals from Finnmarken (NGB13868 and NGB14283), whereas all other accessions formed a second cluster (data not shown). Removing the highly deviating Finnmarken accessions, $K=4$ had the highest support (but with strong support also for $K=2$ ). At this level of clustering some accessions were grouped solely into a single cluster (though with limited geographic structure), but the individuals in general showed a higher degree of admixture than the Southern accessions at the same level of clustering (Fig. 2e).

PCA plots based on genotypes for each separate individual of the accessions illustrate the difference in accession distinction further (Fig. 6). In the Southern dataset individuals from the same country and even accession grouped together to a large extent (Fig. 6a). In the Northern data set two accessions (NGB14297 and R 2136) grouped separately, but the individuals from the remaining accessions, originating from all countries, were mixed (Fig. 6b). Looking at dispersion in PC space, the Norwegian accession NGB477 is much more homogenous than the other accessions (Additional file 1), but excluding this accession, the PC dispersion of individuals from accessions in the Northern group is significantly higher than that of individuals in the Southern group (unpaired $t$-test, $P<0.05$ ). This is also reflected by the average within-accession diversity $\mathrm{H}_{\mathrm{E}}$ that is significantly higher in the Northern group than in the Southern group (unpaired $t$-test, $P<0.01$ ). Additionally, $\mathrm{F}_{\mathrm{ST}}$ values between accessions in the Northern group (average 0.067) were significantly lower than values between accessions in the Southern group (average 0.090) (unpaired $t$-test, $P<<0.001$ ).

In summary, accessions from the Southern group are genetically differentiated from each other and with somewhat lower within-accession diversity. The Northern group consists both of some accessions clearly differentiated from others but with the majority of accessions belonging to virtually the same population.

\section{The effect of pooling on the detection of population structure}

The structure detected when analysing the in silico pooled data in general showed good agreement with the structure detected when analysing the separate individuals dataset. However, the level of detail at which structure could be detected was lower for the pooled data set (Additional file 14). $\Delta K$ and CLUMPP $\mathrm{H}^{\prime}$ values typically supported lower levels of clustering for pooled than un-pooled data (Additional file 5). A notable exception was the Northern accessions where a high number of clusters were supported (8 including the Finnmarken accessions and 7 excluding them). However, level of clustering above $K=2$ added no biologically relevant information and only resulted in split ancestry of accessions. In the southern group no population structure could be detected for the pooled data set (Additional file 14). One consequence of the in silico pooling thus seems to be a reduced power to detect geographic structuring.

\section{Discussion}

\section{Genetic diversity in the genus Secale}

In this study we demonstrate that SNP markers developed for rye elite cultivars can be applied to landrace varieties as well as feral and wild ryes. In contrast to many previous investigations of rye, using single individuals or pooling schemes, we also assess within-accession genetic diversity and structure in rye populations. One of the most striking results is the wide distribution of the diversity found within accessions of rye. AMOVA showed that the absolute majority of the genetic diversity was present within accessions with only little additional diversity present within taxon, types or geographic regions. From a genetic diversity perspective conservation of landrace rye from a reasonably limited regional area might be as efficient as conserving additional taxon or landraces from a wide geographic range, at least when Northern accessions are concerned. The cross-pollinating reproductive habit of rye most likely plays a contributing role in this. 
Our results regarding genetic diversity in different taxa must, however, be interpreted with some caution. In our panel, the genetic diversity is higher in cultivated rye than in feral, and wild $S$. strictum accessions have the lowest diversity (Table 2). This is contrary to the expectation of higher genetic diversity in wild or feral accessions, unaffected by a domestication bottleneck and observed in many other species [e.g. 51-53]. This unexpected difference could be due to ascertainment bias as the SNP panel was originally developed for elite cultivars of cultivated rye. Strong effects of ascertainment bias when comparing materials with different improvement status have been noted previously in both barley and wheat $[31,54,55]$.

We do consider ascertainment bias in our material to be present, but not affecting different taxa very differently. First of all, the higher gene flow of outcrossing crops such as rye lower the effects of ascertainment bias as genetic diversity is less structured and more evenly distributed within and between taxa (Fig. 2). Second we note that almost all markers detect diversity and that the proportions of monomorphic markers are rather low in all taxa with the exception of S. africanum and S. strictum. Third the minor allele frequency distribution was similar in different status groups (Additional file 4) indicating that the ascertainment bias had comparable effects on the different status groups. Additionally, merging SNPs into haplotypes has been shown to alleviate the effects of ascertainment bias when present [49]. Our merging of SNPs to haplotypes had, for most taxa, little effect on the relative differences in diversity. Only $S$. africanum and $S$. strictum showed a relative increase in diversity when SNPs were merged into haplotypes of increasing length (Fig. 1). Based on this we believe that ascertainment bias is primarily a problem in the cases of S. africanum and S. strictum. A higher diversity in cultivated rye than in feral types has also been found using less biased markers such as AFLPs [14], SSRs [15] and ISSRs [56] . This suggests that the limited diversity detected in at least feral ryes is not primarily due to ascertainment bias but that the feral genetic diversity might rather be poorly represented in genebank collections.

The within-accession diversity measures largely mirror those for total diversity, with lower $\mathrm{H}_{\mathrm{E}}$ in the wild and feral taxa. The exception is the wild S. vavilovii, with average within-accession $\mathrm{H}_{\mathrm{E}}$ in same range as cultivated $S$. cereale and significantly higher than the feral taxa. Among the cultivated accessions, most accessions have similar levels of diversity and no significant differences were found between the different agro-climatic regions. Somewhat surprising, $\mathrm{H}_{\mathrm{E}}$ was not lower in the commercial cultivars than in the landraces. Similar observations were, however, made by Persson \& von Bothmer [22] using isozyme markers. This is contrary to inbreeding crops, where landraces regularly have much higher within-accession diversity than commercial breeds [57]. The accession NGB13868 has a markedly low $\mathrm{H}_{\mathrm{E}}$. This accession is known to originate from only a few seeds, which explains its reduced diversity [58].

As an alternative measure of within-accession diversity we studied PC dispersion. Pairs of individuals which are genetically similar will be geometrically close within PC space. Comparing PC dispersions between accessions gives a measure of the difference in relative diversity. The variance of the accession's pair-wise distances further reveals if the distances giving rise to the PC dispersion are randomly distributed. PC dispersion means are mostly correlated to $\mathrm{H}_{\mathrm{E}}$, but not necessarily so. For example, the accession NGB477, has high $\mathrm{H}_{\mathrm{E}}$ but deflated $\mathrm{PC}$ dispersion means. This means that although the accession contains a lot of diversity, all individuals are relatively similar to each other. Some accessions have inflated PC dispersion variance, caused by two or more individuals in the accession being highly similar. If two individuals have increased similarity an origin as siblings from the same ear could be expected, not an unlikely situation with low population sizes maintained in genebank. Very highly similar or identical individuals, however, could be considered clones originating from the same embryo. One explanation could be presence of polyembryonic seeds [59], giving rise to several shoots, accidently sampled as different individuals. Re-analysing our data, with the highly similar individuals removed, showed that their effect on genetic diversity and structuring was all non-significant.

\section{Insights into Secale taxonomy}

The taxonomic classification within the genus Secale was long elusive. However, most recent molecular studies agree of a three-species model with $S$. sylvestre, S. strictum and $S$. secale $[15,16,56$, but contrasting 12$)$. This taxonomic classification is also in agreement with Frederiksen and Petersen's [10] morphology-based taxonomy. Our data support this classification, although $S$. sylvestre was not included in the study. We furthermore find support for the sometimes suggested species $S$. africanum and $S$. vavilovii (see e.g. [11] and references therein) as subspecies of S. strictum and S. secale respectively. In this study, the $S$. africanum accession clustered both in STRUCTURE and with PCA together with the true S. strictum accessions. The relatively low genetic distance (0.051) and $\mathrm{F}_{\mathrm{ST}}$ value $(0.133)$ between $S$. africanum and S. strictum, smaller than to any other taxa, reinforced the close relationship. Although found only in South Africa S. africanum is inter-fertile with the remaining Secale taxa [60]. The proximity between $S$. africanum and $S$. strictum accessions strengthen the hypothesis that the odd location of $S$. africanum, far away from the distribution of other Secale taxa, is better explained by human activities, 
namely the introduction of rye and its weeds in South Africa by European settlers, rather than it being a remnant of an originally much larger distribution area of Secale [10].

S. vavilovii plants are fully shattering, with ears that disarticulate spontaneously, and can be considered a wild subspecies and not just a weedy or feral type [17]. Nonetheless, S. vavilovii clusters closely with cultivated S. cereale accessions both in the STRUCTURE analysis and PCA (Fig. 2a, Fig. 4, Additional file 6) and must be considered to be a subspecies of $S$. cereale. The low $\mathrm{F}_{\mathrm{ST}}$ and genetic distance between $S$. cereale and S. vavilovii (0.016 and 0.017 respectively) attest to their relatedness and low genetic differentiation (Table 4). Cultivated rye has been proposed to derive from either $S$. strictum (Persl.) [= S. montanum Guss.] or from S. vavilovii in Eastern Turkey and Armenia [17, 61]. Our results confirm previous studies $[11,15]$ suggesting that $S$. vavilovii is the most likely wild ancestor of cultivated rye.

The classification of S. secale subspecies has been more inconclusive, particularly the relationship of feral and cultivated rye forms [7-9]. Our analyses support grouping the cultivated and the feral ryes as the same species and that all these taxa cross-hybridise to some degree. Although feral rye present a certain degree of genetic distinctiveness from both cultivated and wild ryes, in congruence with Chikmawati et al. [14], we conclude that geographic origin is more relevant for population structure than taxonomic subspecies classification. In our dataset some feral ryes are more similar to cultivated rye from the same region than landraces are to other landraces from different regions. For example, the S. afghanicum accession R 777 has a very low $\mathrm{F}_{\mathrm{ST}}(0.096)$ from the Afghan landrace PI 220119; the Spanish S. segetale R 779 has one of its lowest pairwise $\mathrm{F}_{\mathrm{ST}}(0.087)$ with the Spanish landrace $\mathrm{R} 785$ (Additional file 7), a value lower than those comparing R 779 with other S. segetale accessions. The potentially mislabelled accession of $S$. strictum (PI 240285) mentioned above is described in the passport data as S. strictum subsp. anatolicum), from Turkey and clusters together with feral and cultivated rye from Turkey, Afghanistan and Pakistan and one cultivated rye from the same region (turquoise in Fig. 2a). A similar pattern is painted in the PCA where, although some feral accessions were genetically distinct enough to constitute their own clusters, most feral accessions clustered with the cultivated landraces from the same regions (for example $S$. segetale from Spain, S. ancestrale from Turkey or S. afghanicum from Afghanistan) rather than with accessions of the same taxon.

Feral rye phenotypes have been described to morphologically diverge quickly from cultivated rye progenitors, especially if cessation of rye cultivation in one region reproductively isolates feral types from and cultivated ones
[62]. In this study we can se how feral ryes share some alleles with both $S$. vavilovii and S. cereale landrace accessions. These results suggest a complex scenario of high introgression between the ryes in the S. cereale - vavilovii group, but with no detectable contribution from the $S$. strictum - S. africanum group.

\section{Geographic structuring of genetic diversity in cultivated rye}

Previous studies of the distribution of genetic diversity in cultivated rye have mainly failed to find any clear geographic patterns [13, 14, 22, 23, 63]. Bolibok-Bragoszewska et al. [24] found separation between Near East rye and European rye but no geographical clustering within Europe. The very low degree of variation distributed between regions, shown by AMOVA, suggests that a large number of markers are needed to identify geographical structure. The SNP panel used here, in combination with the genotyping of multiple individuals from each accession, does, however, seem sufficient to cluster European landraces geographically (Figs. $2 \mathrm{c}$ and 3). It is also clear that although $80 \%$ or more of the genetic diversity present can be accounted for in pooled samples, the power to detect geographic structure is reduced by pooling of samples before genotyping. We were consistently able to detect higher levels of clustering using our un-pooled data set than we were with our in silico pooled data. This supports the results of computer simulations [64].

The five major groups of landrace rye detected, partly reflects the agro-climatic zones of Europe (as e.g. proposed by Bouma [41]). However, a distinct cluster of accessions ranging from Scotland in the North to Morocco in South along the Atlantic coast represents areas with rather different climates (blue in Fig. 3). Likewise, a cluster of accessions from Scandinavia, Finland and Russia also span across agro-climatic zones (yellow in Fig. 3). Thus, the geographic distribution of genetic diversity is not only formed by agro-climatic suitability, but also through pollen dispersal and seed exchange in areas with closer cultural contacts.

The smallest cluster, consisting of a single Norwegian and a single Swedish landrace, both from the Finnmarken area stood out as the geographically most local group. Most of the individuals in these accessions also shared the same, and amongst cultivated rye unique, chloroplast genotype. The distinctiveness of landrace rye from this area from the majority of Scandinavian rye was previously noted by Persson et al. [23]. The rye cultivated in this region is strongly connected to historical migrations of people. This region of Norway and Sweden is known as the Finnmarken area, the area where Finnish farmers settled after leaving their native country in the $16^{\text {th }}$ century. It is well known that the Finnish immigrants practiced slash-and-burn cultivation of rye in this area and 
also brought seed with them from their native area [6]. The accession NGB13868 also has the local name "Finnrug", meaning Finnish rye. Rye aimed for slash-and-burn cultivation is often characterized by extreme tillering capacity, a trait also observed in the "Finn-rug" accession [58]. We were, however, unable to detect any significant clustering between the Finnmarken rye and any of the Finnish accessions included in this study. It should be noted, however, that our study also includes other Scandinavian rye landraces with passport data describing them as slash-and-burn types [23]. These accessions do not cluster genetically with the accessions from Finnmarken, but instead with other Nordic accessions aimed for cultivation on ordinary cropland. One hypothesis is that the rye accessions from the isolated region of Finnmarken represent an older type of slash-and-burn rye, whereas the other slash-and-burn rye landraces in Fennoscandia have been outcrossed and mixed with more abundant rye types.

The population structure detected suggests that European rye landraces could have originated in different places. According to the $K=9$ STUCTURE model (Fig. 2), the yellow cluster that includes most Scandinavian and Russian accessions also contains a part of the diversity of some $S$. vavilovii individuals from Afghanistan as well as feral S. segetale and S. afghanicum from the same country. In a study screening RAPDs in a panel of worldwide breed and landrace ryes, Ma et al., [63] found that northern European rye accessions (Scandinavia and Germany) clustered together and in this cluster a landrace from Afghanistan was also included. It is possible that the rye introduced to Russia and Northern Europe originated in the area around Afghanistan and was introduced through a route north of the Caspian and Black seas, whereas rye in the south of Europe originated in the Turkish area. Alternatively, rye could have originated in one core area in the Near East and, after spreading to Europe, gone through bottlenecks and distinct selection pressures leading to an adaptation to different regions. Such population dynamics could also generate the distinct clusters observed in cultivated rye. A strong correlation between genetic structuring and agro-climatic regions would then be expected. We observe increasing genetic diversity within landraces from more northern latitudes (Additional file 10). In spite of necessary adaption to a climate much different from the climate at the center of origin, rye cultivated in the North contain as much diversity as rye cultivated close to the center of origin. Possibly the more intense rye cultivation in the North until recent time has contributed to maintain diversity in landraces.

A distinguishing feature during adaption of rye in Europe would have been selection for winter versus spring-sown ryes, with the South and West of Europe ryes being predominantly spring (or facultative) types and northern European ryes being winter types. Ma et al. [63] found that the winter vs spring habit generated two very distinct clades in their panel of 42 elite breeds. Contrastingly, in their analysis of Swedish historical and genebank kept landraces, Hagenblad et al. [65] did not observe any separation between winter and spring types of rye. In this study, PCA of cultivated rye separated spring from winter varieties along the $1^{\text {st }} \mathrm{PC}$ although some overlap was observed (Additional file 15). It is possible that in different regions of Europe the choice of cultivating spring or winter rye reflected local climatic specificities and agronomic practices leading to a slight genetic differentiation over time. We note also that STUCTURE groups in Central and South Eastern Europe contain both spring and winter forms.

The STRUCTURE assignment of the three modern varieties reflected their breeding history. NGB 6431 'Kungs II' clustered among landraces from Northern Europe. This variety was breed in Sweden from landraces from Northern Germany, possibly pollinated with Swedish landraces. PI428373 'Petkus' spring rye, clustered among other spring rye landraces from Western Europe. PI 323382 'Imperial' clustered among landraces from the Central Europe. 'Imperial' is an American variety selected from the landrace 'Schlanstedt', originating in central Germany.

Mitochondrial and chloroplast markers have been used to contrast maternal spread (in plants through seeds) with biparental spread (through both seed and pollen). In rye, exclusively maternal transmission of chloroplasts has been detected in some studies [66, 67]; while others have reported biparental inheritance[68-70]). In rye the structure detected using cPSSR should thus probably be considered to reflect both seed spread and to some extent pollen movement. Studies combining nuclear and chloroplast markers sometimes provide similar information about a species' evolutionary narrative, but can potentially provide scenarios that are contrasting, for example in rice [71], Carex [72], almond [73] and Arabidopsis [74]. We carefully analysed all electropherograms for the cpSSRs. However, some alleles detected differed by only a single base-pair and errors resulting from PCR amplification cannot be ruled out. The cPSSR data, based on only a few markers, and DAPC clustering must therefore be considered with caution. The structure could, however, lend additional support to the structure as determined by the SNP markers. Except for S. strictum and africanum, we observed no taxonomic clustering, again supporting the inclusion of all feral taxa, $S$. vavilovii and cultivated rye in the same species. Among the cultivated landraces, accessions from Western Europe, Northern Europe and South Eastern Europe formed three groups, suggesting seed exchange within these areas and supporting nuclear SNP geographic patterns. Among the accessions from Finnmarken all individuals of NGB13868 and half of the individuals in NGB14283, had a distinct cpgenotype not found elsewhere among cultivated rye. This 
suggests a foreign, but unknown, origin for these landraces. Screening additional landraces, especially from remote areas in Finland, with the cpSSR markers, or the full set of SNP markers, could shed light on the origin of these ryes and the possible connection to Finnish migration in the $16^{\text {th }}$ century.

\section{Contrasting genetic structuring in regions reflects past cultivation intensity}

Our results demonstrate how cultivation practices can affect how genetic diversity is distributed in regions. Geographic structuring was investigated at a regional level using two contrasting groups of accessions. The Southern group consisted of spring type rye from Iberia and Morocco, all belonging to the same Structure group (blue in Fig. 3). The Northern group consisted of winter type rye from Fennoscandia and Western Russia, belonging to the yellow Structure group. We concluded from PCA, $\mathrm{F}_{\mathrm{ST}}$ and $\mathrm{PC}$ dispersion analysis that accessions in the Southern group were much more genetically distinct from each other than the majority of accessions in the Northern group (Fig. 6; Additional file 1 and Additional file 3).

A distinct clustering of landraces suggests more limited gene flow between accessions. In Iberia and Morocco rye is only cultivated as a minor crop in mountainous regions $[75,76]$. Contrastingly, in Fennoscandia rye was the dominant food crop from the $16^{\text {th }}$ century until the mid- $20^{\text {th }}$ century [5], which would allow more frequent gene flow between populations. From our data we cannot say if the higher gene flow in Northern group is due to more seed exchange, more pollen dispersal or both. Unfortunately, the power from the limited number of maternally inherited markers is not enough to detect different patterns of pollen and seed dispersal within this region. From studies of landrace dynamics in inbreeding crops, such as pea [57] and rice [77] we do, however, know that isolation by distance or decreased cultivation intensity can rapidly cause genetic drift and differentiation between populations. These processes are probably slower in cross-pollinating crops, but the same trend that can be seen in the Southern group and could be expected in other areas where rye cultivation declines.

\section{Availabiliy of supporting data}

The SNP and chloroplast SSR genotyping data generated for this paper are available at the Dryad data archive (https://datadryad.org/resource/doi:10.5061/dryad.tn2fb).

\section{Additional files}

Additional file 1: Accessions used in this study, genebank provider, taxon, provenance and growth habit and genetic diversity measures. (XLSX $29 \mathrm{~kb}$ )
Additional file 2: List of SNPs genotyped. Assembly, contig and position in contig is indicated in SNP names. The SNP within brackets and flanking sequences are shown. (XLSX $65 \mathrm{~kb}$ )

Additional file 3: Minor allele frequency distributions for A) $S$. cereale, B) S. strictum, C) S. vavilovii, D) S. africanum, E) $S$. dighoricum, F) S. ancestrale, G) S. afghanicum and H) S. segetale respectively. Bars show the observed number of markers with a given minor allele frequency. (PDF $51 \mathrm{~kb}$ )

Additional file 4: Minor allele frequency distributions for A) Wild rye, B) Feral rye and C) Cultivated rye respectively. Bars show the observed number of markers with a given minor allele frequency and the red line depicts the distribution expected under neutrality. (PDF $6 \mathrm{~kb}$ )

Additional file 5: Determination of the best-fit STRUCTURE models by determination of $\Delta K$ values [46] and $\mathrm{H}^{\prime}$ values obtained with CLUMPP [45] for data analysed as separate individuals and individuals pooled in silico. (PDF $969 \mathrm{~kb}$ )

Additional file 6: STRUCTURE output for $K$ models 2 to 12 for the complete set of accessions. Accessions are organized by taxon. (PDF $11269 \mathrm{~kb}$ )

Additional file 7: Pairwise $\mathrm{F}_{\mathrm{ST}}$ values between pairs of accessions. (XLSX $45 \mathrm{~kb}$ )

Additional file 8: Correlation between geographic distance (km) and genetic distance $\left(D_{S}\right)$ [77] between individual rye accessions. (PDF $1415 \mathrm{~kb})$

Additional file 9: Correlation between longitude $\left(^{\circ}\right)$ and genetic diversity $\left(\mathrm{H}_{\mathrm{E}}\right)$ in rye accessions. (PDF $598 \mathrm{~kb}$ )

Additional file 10: Correlation between latitude $\left(^{\circ}\right)$ and genetic diversity $\left(H_{E}\right)$ in rye accessions. (PDF $622 \mathrm{~kb}$ )

Additional file 11: Correlation between distance to origin of domestication $(\mathrm{km})$ and genetic diversity $\left(\mathrm{H}_{\mathrm{E}}\right)$ in rye accessions. (PDF $670 \mathrm{~kb}$ )

Additional file 12: DAPC output based on chloroplast SSRs for $K$ models $\mathbf{2}$ to $\mathbf{6}$ for the complete set of accessions. Each bar is one accession averaged on 4 to 6 individuals. Accessions are organized by taxon. A) $K=2$, B) $K=3$, C) $K=4, D K=5$, E) $K=6$ (PDF $11334 \mathrm{~kb}$ )

Additional file 13: Geographical distribution of cultivated rye landrace clusters according to the DAPC $K=\mathbf{5}$ model. Each landrace is depicted as a pie chart with the proportional membership of its alleles to each one of the five clusters. (JPG $1027 \mathrm{~kb}$ )

Additional file 14: Clustering of rye accessions based on STRUCTURE analysis of in silico pooled data for $K$ values corresponding to those shown in Fig. 2. A) $K=9$ model for the complete set of accesions. B) $K=7$ model for the Southern set of Moroccan, Portuguese and Spanish landraces. C) $K=4$ model for the Northern set of Fennoscandian and Russian landraces. (PDF $61 \mathrm{~kb}$ )

Additional file 15: PCA of cultivated rye accessions coloured by their growth habit (winter vs spring). (PDF $1436 \mathrm{~kb}$ )

Competing interests

The authors declare no conflict of interest.

Authors' contributions

$H R O, J H$ and MWL designed the project. Lab work was performed by HRO. Data was analyzed by HRO, JH and NEGF. HRO, JH and MWL wrote the manuscript with contributions by NEGF. All authors have read and approved the final version of the manuscript.

\section{Acknowledgements}

This work was funded by the Lagersberg foundation. HRO was funded by the Lagersberg foundation, the Sven och Lilly Lawskis Fond för Naturvetenskaplig Forskning and the "Genomics and Evolutionary Biology" project co-financed by North Portugal Regional Operational Programme 2007/2013 (ON.2 - O Novo Norte), under the National Strategic Reference Framework (NSRF), through the European Regional Development Fund (ERDF). Per Larsson and Maria Lundström are acknowledged for statistical and technical assistance respectively. 


\section{Author details}

IFM Biology, Linköping University, SE-581 83 Linköping, Sweden. ${ }^{2} \mathrm{CIBIO}$-Research Centre in Biodiversity and Genetic Resources, Campus Agrário de Vairão. R. Padre Armando Quintas, 4485-661 Vairão, Portugal. ${ }^{3}$ Nordiska Museet, Swedish Museum of Cultural History, SE-643 98 Julita, Sweden. ${ }^{4}$ Present Address: Faculty of Life Sciences, The University of Manchester. Manchester Institute of Biotechnology, 131 Princess Street, M1 7DN Manchester, UK.

Received: 8 July 2015 Accepted: 11 January 2016

Published online: 19 January 2016

\section{References}

1. Madej LJ. Worldwide trends in rye growing and breeding. Vortr Pflanzenzucht. 1996;35:1-6.

2. Schittenhelm S, Kraft M, Wittich KP. Performance of winter cereals grown on field-stored soil moisture only. Eur J Agron. 2014;52:247-58.

3. Behre K-E. The history of rye cultivation in Europe. Veg Hist Archaeobot. 1992;1:141-56

4. Grabowski R. Changes in cereal cultivation during the Iron Age in southern Sweden: a compilation and interpretation of the archaeobotanical material. Veg Hist Archaeobot. 2011;20:479-94.

5. Palm, LA \& Linde M. Sverige 1570-1805: befolkning, jordbruk, jordägande. Göteborg: Institutionen för historiska studier. Göteborgs universitet; 2012-2014.

6. Ahokas H. Crop evolution under fire: the past cultivation with sequential kytö burning selected against the shattering weedy forms and comparison between Finnish kytö and Ethiopian guie. Helsinki: Kave; 2012.

7. Khush GS. Cytogenetic and evolutionaty studies in Secale. II. Interrelationships of the wild species. Evolution. 1962;16:484-96.

8. Sencer HA, Hawkes JG. On the origin of cultivated rye. Biol J Linn Soc. 1980; 13:299-313.

9. Hammer K. Breeding system and phylogenetic relationships in Secale L. Biol Zentralbl. 1990;109:45-50.

10. Frederiksen S, Petersen G. A taxonomic revision of Secale (Triticeae, Poaceae). Nord J Bot. 1998;18:339-420.

11. De Bustos A, Jouve N. Phylogenetic relationships of the genus Secale based on the characterisation of rDNA ITS sequences. Plant Syst Evol. 2002;235: 147-54.

12. Shang HY, Baum BR, Wei YM, Zheng Y. The 5 S rRNA gene diversity in the genus Secale and determination of its closest haplomes. Genet Resour Crop Evol. 2007:54:793-806.

13. Chikmawati T, Skovmand B, Gustafson JP. Phylogenetic relationships among Secale species revealed by amplified fragment length polymorphisms. Genome. 2005;48:792-801.

14. Chikmawati T, Miftahudin M, Skovmand B, Gustafson JP. Amplified fragment length polymorphism-based genetic diversity among cultivated and weedy rye (Secale cereale L.) accessions. Genet Resour Crop Evol. 2012;59:1743-52.

15. Ren $\mathrm{TH}$, Chen F, Zou YT, Jia YH, Zhang HQ, Yan BJ, et al. Evolutionary trends of microsatellites during the speciation process and phylogenetic relationships within the genus Secale. Genome. 2011:54:316-26.

16. Marques A, Banaei-Moghaddam AM, Klemme S, Blattner FR, Niwa K, Guerra $M$, et al. B chromosomes of rye are highly conserved and accompanied the development of early agriculture. Ann Bot. 2013;112:527-34.

17. Zohary D, Hopf M, Weiss E. Domestication of Plants in the Old World, 4th edition. 4th ed. Oxford: Oxford University Press; 2012.

18. Frederiksen S, Petersen G. Morphometrical analyses of Secale (Triticeae, Poaceae). Nor J Bot. 1997;17:185-98.

19. Tang ZX, Ross K, Ren ZL, Yang ZJ, Zhang HY, Chikmawati T, Miftahudin M, Gustafson JP. Rye. In Kole C (ed) Wild crop relatives: genomic and breeding resources. 2011; New York, Springer pp: 367-396.

20. Camacho Villa TC, Maxted N, Scholten M, Ford-Lloyd B. Defining and identifying crop landraces. Plant Genet Resour. 2006;3:373-84.

21. Feldman M. Origins of Cultivated Wheat. In: Bonjean AP, Angus WJ, editors. The world wheat book: a history of wheat breeding. Paris: Intercept. Lavoisier Publishing; 2001.

22. Persson K, Bothmer R. Assessing the Allozyme Variation in Cultivars and Swedish Landraces of Rye (Secale cereale L.). Hereditas. 2000;132:7-17.

23. Persson K, Díaz O, Bothmer R. Extent and patterns of RAPD variation in landraces and cultivars of rye (Secale cereale L.) from Northern Europe. Hereditas. 2001;134:237-43.
24. Bolibok-Brągoszewska H, Targońska M, Bolibok L, Kilian A, RakoczyTrojanowska M. Genome-wide characterization of genetic diversity and population structure in Secale. BMC Plant Biol. 2014;14:184.

25. Ganal MW, Altmann T, Röder MS. SNP identification in crop plants. Curr Opin Plant Biol. 2009;12:211-7.

26. McNally KL, Childs KL, Bohnert R, Davidson RM, Zhao K, Ulat VJ, et al. Genome-wide SNP variation reveals relationships among landraces and modern varieties of rice. Proc Natl Acad Sci U S A. 2009;106:12273-8.

27. Caicedo AL, Williamson SH, Hernandez RD, Boyko A, Fledel-Alon A, York TL, et al. Genome-wide patterns of nucleotide polymorphism in domesticated rice. PLoS Genet. 2007;3:1745-56.

28. Yan J, Shah T, Warburton ML, Buckler ES, McMullen MD, Crouch J. Genetic characterization and linkage disequilibrium estimation of a global maize collection using SNP markers. PLoS One. 2009;4:e8451.

29. Van Inghelandt D, Reif JC, Dhillon BS, Flament P, Melchinger AE. Extent and genome-wide distribution of linkage disequilibrium in commercial maize germplasm. Theor Appl Genet. 2011:123:11-20.

30. Allen AM, Barker GL, Berry ST, Coghill JA, Gwilliam R, Kirby S, et al. Transcript-specific, single-nucleotide polymorphism discovery and linkage analysis in hexaploid bread wheat (Triticum aestivum L.). Plant Biotechnol J. 2011;9:1086-99.

31. Oliveira HR, Hagenblad J, Leino MW, Leigh FJ, Lister DL, Jones MK. Wheat in the Mediterranean revisited - tetraploid wheat landraces assessed with elite bread wheat single-nucleotide polymorphism markers. BMC Genet. 2014;15:54.

32. Close TJ, Bhat PR, Lonardi S, Wu Y, Rostoks N, Ramsay L, et al. Development and implementation of high-throughput SNP genotyping in barley. BMC Genomics. 2009;10:582.

33. Comadran J, Ramsay L, MacKenzie K, Hayes P, Close TJ, Muehlbauer G, et al. Patterns of polymorphism and linkage disequilibrium in cultivated barley. Theor Appl Genet. 2011;122:523-31.

34. Forsberg NEG, Russell J, Macaulay M, Leino MW, Hagenblad J. Farmers without borders - genetic structuring in century old barley (Hordeum vulgare). Heredity. 2014;114:195-206.

35. Li Y, Haseneyer G, Schön CC, Ankerst D, Korzun V, Wilde P, et al. High levels of nucleotide diversity and fast decline of linkage disequilibrium in rye (Secale cereale L.) genes involved in frost response. BMC Plant Biol. 2011;11:6.

36. Haseneyer G, Schmutzer T, Seidel M, Zhou R, Mascher M, Schön CC, et al. From RNA-seq to large-scale genotyping - genomics resources for rye (Secale cereale L.). BMC Plant Biol. 2011;11:131.

37. Varshney RK, Beier U, Khlestkina EK, Kota R, Korzun V, Graner A, et al. Single nucleotide polymorphisms in rye (Secale cereale L.): discovery, frequency, and applications for genome mapping and diversity studies. Theor Appl Genet. 2007:114:1105-16.

38. Miedaner $T$, Hübner M, Korzun $V$, Schmiedchen B, Bauer E, Haseneyer G, et al. Genetic architecture of complex agronomic traits examined in two testcross populations of rye (Secale cereale L.). BMC genomics. 2012;13

39. McGrath S, Hodkinson TR, Salamin N, Barth S. Development and testing of novel chloroplast microsatellite markers for Lolium perenne and other grasses (Poaceae) from de novo sequencing and in silico sequences. Mol Ecol Notes. 2006;6:449-52.

40. Ishii T, Mori N, Ogihara Y. Evaluation of allelic diversity at chloroplast microsatellite loci among common wheat and its ancestral species. Theor Appl Genet. 2001;103:896-904.

41. Bouma E. Development of comparable agro-climatic zones for the international exchange of data on the efficacy and crop safety of plant protection products. OEPP/EPPO Bulletin. 2005;35:233-8.

42. Liu K, Muse SV. PowerMarker: an integrated analysis environment for genetic marker analysis. Bioinformatics. 2005;21:2128-9.

43. Peakall R, Smouse PE. GenAlEx 6.5: genetic analysis in Excel. Population genetic software for teaching and research - an update. Bioinformatics. 2012;28:2537-9

44. Pritchard J, Stephens M, Donnelly P. Inference of population structure using multilocus genotype data. Genetics. 2000;155:945-59.

45. Jakobsson M, Rosenberg NA. CLUMPP: a cluster matching and permutation program for dealing with label switching and multimodality in analysis of population structure. Bioinformatics. 2007;23:1801-6.

46. Evanno G, Regnaut S, Goudet J. Detecting the number of clusters of individuals using the software STRUCTURE: a simulation study. Mol Ecol. 2005;14:2611-20. 
47. R development core team. R: A language and environment for statistical computing. Vienna, Austria: R Foundation for Statistical Computing; 2013.

48. Jombart T, Devillard S, Balloux F. Discriminant analysis of principal components: a new method for the analysis of genetically structured populations. BMC Genet. 2010;11:1-15.

49. Conrad DF, Jakobsson M, Coop G, Wen X, Wall JD, Rosenberg NA, et al. A worldwide survey of haplotype variation and linkage disequilibrium in the human genome. Nat Genet. 2006;38:1251-60.

50. Frascaroli $E$, Canè MA, Pè ME, Pea G, Landi P. Characterization of heterotic quantitative trait loci in maize by evaluation of near-isogenic lines and their crosses at two competition levels. Theor Appl Genet. 2012;124:35-47.

51. Doebley J. The genetics of maize evolution. Annu Rev Genet. 2004;38:37-59.

52. Zhu Q, Zheng X, Luo J, Gaut BS, Ge S. Multilocus analysis of nucleotide variation of Oryza sativa and its wild relatives: severe bottleneck during domestication of rice. Mol Biol Evol. 2007:24:875-88.

53. Haudry A, Cencí A, Ravel C, Bataillon T, Brunel D, Poncet C, et al. Grinding up wheat: a massive loss of nucleotide diversity since domestication. Mol Biol Evol. 2005;24:1506-17.

54. Moragues M, Comadran J, Waugh R, Milne I, Flavell AJ, Russell JR. Effects of ascertainment bias and marker number on estimations of barley diversity from high-throughput SNP genotype data. Theor Appl Genet. 2010;120:1525-34

55. Russell J, Dawson IK, Flavell AJ, Steffenson B, Weltzien E, Booth A, et al. Analysis of $>1000$ single nucleotide polymorphisms in geographically matched samples of landrace and wild barley indicates secondary contact and chromosome-level differences in diversity around domestication genes. New Phytol. 2011;191:564-78.

56. Shang H, Wei $Y$, Wang $X$, Zheng $Y$. Genetic diversity and phylogenetic relationships in the rye genus Secale L. (rye) based on Secale cereale microsatellite markers. Genet Mol Biol. 2006;29:685-91.

57. Leino MW, Boström E, Hagenblad J. Twentieth-century changes in the genetic composition of Swedish field pea metapopulations. Heredity. 2012;110:338-46.

58. Tvengsberg PM. Det värmlandsfinske svedjebruket. In: Larsson B, editor. Svedjebruk och röjningsbränning i Norden. Stockholm: Nordiska museet; 1995. p. 109-18.

59. Kostoff D. Frequency of polyembryony and chlorophyll deficiency in rye. CR Acad Sci URSS. 1939:24:479-82.

60. Reddy P, Appels R, Baum BR. Ribosomal DNA spacer-length variation in Secale spp. (Poaceae). Plant Syst Evol. 1990;171:205-20.

61. Altpeter F, Korzun V. Rye. In: Pua EC, Davey MR, editors. Biotechnology in Agriculture and Forestry - Transgenic Crops IV. Berlin: Springer; 2007.

62. Burger JC, Holt JM, Ellstrand NC. Rapid phenotypic divergence of feral rye from domesticated cereal rye. Weed Sci. 2007;55:204-11.

63. Ma R, Yli-Mattila T, Pulli S. Phylogenetic relationships among genotypes of worldwide collection of spring and winter ryes (Secale cereale L.) determined by RAPD-PCR markers. Hereditas. 2004;140:210-21.

64. Fogelqvist J, Niittyvuopio A, Agren J, Savolainen O, Lascoux M. Cryptic population genetic structure: the number of inferred clusters depends on sample size. Mol Ecol Resour. 2010;10:314-23.

65. Hagenblad J, Zie J, Leino MW. Exploring the population genetics of genebank and historical landrace varieties. Genet Resour Crop Evol. 2012;59:1185-99.

66. Vedel F, Quetier F, Cauderon Y, Dosba F, Doussinault G. Studies on maternal inheritance in polyploid wheats with cytoplasmic DNAs as genetic markers. Theor Appl Genet. 1981;59:239-45.

67. Corriveau JL, Coleman AW. Rapid screening method to detect potential biparental inheritance of plastid DNA and results for over 200 angiosperm species. Am J Bot. 1988;75:1443-58.

68. Fröst S, Vaivars L, Carlbom C. Reciprocal extrachromosomal inheritance in rye (Secale cereale L.). Hereditas. 1970;65:251-60.

69. Soliman K, Fedak G, Allard RW. Inheritance of organelle DNA in barley and Hordeum X Secale intergeneric hybrids. Genome. 1987;29:867-72.

70. Mogensen HL, Rusche ML. Occurrence of plastids in rye (Poaceae) sperm cells. Am J Bot. 2000;87:1189-92.

71. Garris AJ, Tai TH, Coburn J, Kresovich S, McCouch S. Genetic structure and diversity in Oryza sativa L. Genetics. 2005;169:1631-8.

72. Puşcaş M, Choler P, Tribsch A, Gielly L, Rioux D, Gaudeul M, et al. Postglacial history of the dominant alpine sedge Carex curvula in the European Alpine System inferred from nuclear and chloroplast markers. Mol Ecol. 2008;17:2417-29.

73. Delplancke M, Alvarez N, Espíndola A, Joly H, Benoit L, Brouck E, et al. Gene flow among wild and domesticated almond species: insights from chloroplast and nuclear markers. Evol Appl. 2012;5:317-29.
74. Picó FX, Méndez-Vigo B, Martínez-Zapater JM, Alonso-Blanco C. Natural genetic variation of Arabidopsis thaliana is geographically structured in the Iberian peninsula. Genetics. 2008;180:1009-21.

75. Lains P, Silveira e Sousa P. Estatística e produção agrícola em Portugal, 1848-1914. Análise Social. 1998;33:935-68.

76. Chevalier A, Marinova E, Peña-Chocarro L. Plants and People: Choices and Diversity Through Time. Oxford, Oxbow Books; 2012.

77. Pusadee T, Jamjod S, Chiang YC, Rerkasem B, Schaal BA. Genetic structure and isolation by distance in a landrace of Thai rice. Proc Natl Acad Sci U S A. $2009 ; 106: 13880-5$

\section{Submit your next manuscript to BioMed Central and we will help you at every step:}

- We accept pre-submission inquiries

- Our selector tool helps you to find the most relevant journal

- We provide round the clock customer support

- Convenient online submission

- Thorough peer review

- Inclusion in PubMed and all major indexing services

- Maximum visibility for your research

Submit your manuscript at www.biomedcentral.com/submit
Biomed Central 